\title{
Unsymmetrical Difunctionalization of Two Different C-H Bonds in One Pot Under Transition-Metal Catalysis
}

\author{
Masahito Murai* (D) \\ Kazuhiko Takai* (D) \\ Division of Applied Chemistry, Graduate School of Natural Science \\ and Technology, Okayama University, 3-1-1 Tsushimanaka, Kita-ku, \\ Okayama 700-8530, Japan \\ masahito.murai@okayama-u.ac.jp \\ ktakai@cc.okayama-u.ac.jp \\ Published as part of the 50 Years SYNTHESIS - Golden Anniversary Issue
}
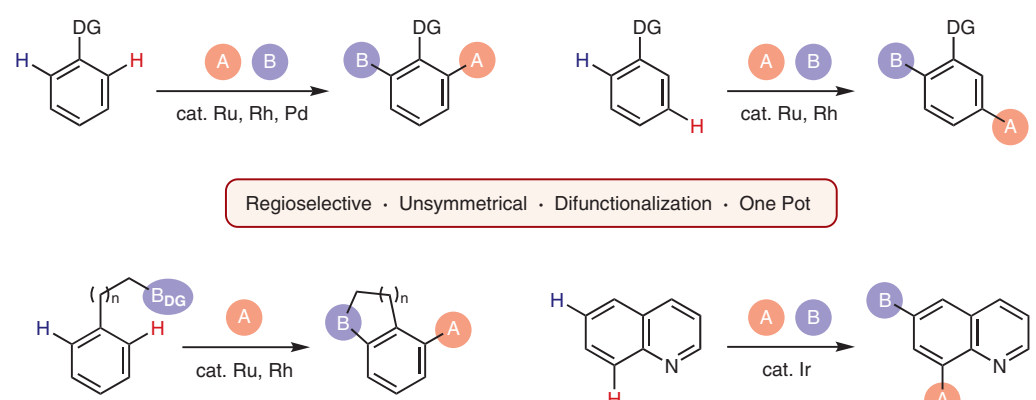

Received: 25.09.2018

Accepted after revision: 28.09.2018

Published online: 27.11 .2018

DOI: 10.1055/s-0037-1611066; Art ID: ss-2018-z0651-sr

License terms: CC $\cong \$$

Abstract Recent advancements in unsymmetrical difunctionalization based on the substitution of two different $\mathrm{C}-\mathrm{H}$ bonds in one-pot are described. Due to the difficulty of controlling reactivity and selectivity, multi-functionalization via substitution of several $\mathrm{C}-\mathrm{H}$ bonds to install different functional groups has been limited until recently, in comparison with well-studied functionalization via sequential addition to unsaturated $\pi$-bonds. This difunctionalization protocol provides an efficient and rapid approach to a library of structurally complicated target molecules through the formation of multiple $\mathrm{C}-\mathrm{X}$ bonds with high atom- and step-economy.

1 Introduction

2 ortho-Selective Functionalization of Two Different $\mathrm{C}-\mathrm{H}$ Bonds Relative to the Directing Group

2.1 Unsymmetrical Difunctionalization with the Introduction of Similar Functional Groups

2.2 Unsymmetrical Difunctionalization with the Introduction of Different Functional Groups

2.3 ortho-Selective Unsymmetrical Difunctionalization Promoted by Two Different Directing Groups Appearing During the Progress of the Reaction

3 ortho/meta-Selective C-H Bond Difunctionalization Relative to the Directing Group

4 Sequential Difunctionalization of Fused Aromatic Compounds and Heterocycles

5 Summary and Outlook

Key words difunctionalization, $\mathrm{C}-\mathrm{H}$ activation, regioselectivity

\section{Introduction}

Selective construction of properly functionalized target molecules from simple and readily available starting materials in a small number of steps is an important goal in synthetic organic chemistry. In addition, the development of sustainable reaction processes with environmentally friendly and operationally safe technology is another key issue. If two or more $\mathrm{C}-\mathrm{X}$ bonds can be formed in a one-pot operation with a single catalyst, a variety of molecules can be created more efficiently. A frequently utilized strategy is the multi-component cascade reaction via inter- and intramolecular addition to unsaturated $\pi$-bonds. Various compounds have been synthesized elegantly with the site- and regioselective installation of appropriate functional groups. ${ }^{1}$ In past decades, transition-metal-catalyzed $\mathrm{C}-\mathrm{X}$ bond formation via $\mathrm{C}-\mathrm{H}$ bond cleavage has received considerable attention as a straightforward method to modify the structure and function of organic molecules. ${ }^{2}$ Because structurally complicated functional molecules are obtained through the activation of generally unreactive ubiquitous $\mathrm{C}-\mathrm{H}$ bonds, they are highly useful in view of atom- and step-economy.

Even though much success has been achieved in this field, one $\mathrm{C}-\mathrm{H}$ bond is usually activated and converted into another functional group in most of the reported transformations. Simultaneous multiple introduction of different functionalities with the activation of several $\mathrm{C}-\mathrm{H}$ bonds existing in one or two molecules remains challenging. The major difficulty arises from site-selective control of multiple $\mathrm{C}-\mathrm{H}$ functionalization, and examples are limited mainly to the introduction of the same functional group. ${ }^{3}$ This is because catalysts and directing groups that control the regioselectivity of the reaction are usually highly specific for one reaction, and therefore additional steps with different catalyst systems are required for the next $\mathrm{C}-\mathrm{H}$ activation to install a different functional group. ${ }^{4}$ In addition, the correct choice of two functionalizing methods, in which the intermediate in the initial functionalization does not hamper the overall reaction sequence, is very important. Therefore, the strategy for unsymmetrical multiple functionalization of $\mathrm{C}-\mathrm{H}$ bonds in a one-pot operation was limited until the last 

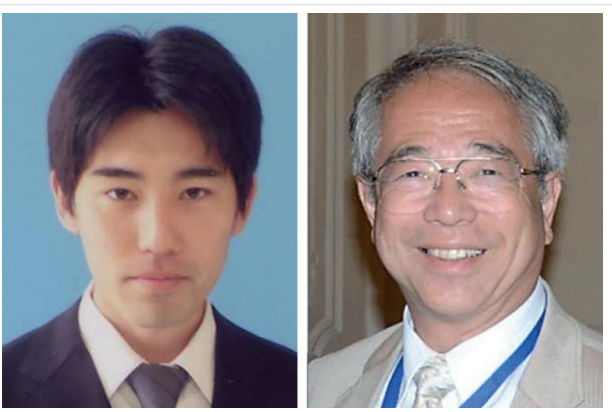

Masahito Murai (left) was born in Okazaki, Aichi, Japan, in 1981. He graduated with a B.Eng. from Kyoto University, and received his Ph.D. from the same university under the supervision of Prof. Kouichi Ohe in 2010. During his Ph.D. studies, he joined Prof. David J. Procter's group at the University of Manchester for three months. Following postdoctoral work as a JSPS research fellow at the Tokyo Institute of Technology with Prof. Munetaka Akita and at the University of California, Santa Barbara with Prof. Craig J. Hawker, he joined Prof. Takai's research group at Okayama University as an assistant professor in 2012. He received the Adeka Award in Synthetic Organic Chemistry, Japan (2013), and The Chemical Society of Japan Award for Young Chemists (2018). His research has focused on the design and development of novel catalytic transformations of unsaturated hydrocarbons and their applications in the synthesis of carbon-based advanced functional materials.

Kazuhiko Takai (right) was born in Tokyo, Japan, in 1954. He received his B.Eng. and Ph.D. from Kyoto University under the direction of Prof. Hitosi Nozaki. In 1981, he was appointed as an assistant professor in Prof. Nozaki's group at Kyoto University, during which time he joined Prof. Clayton H. Heathcock's group at the University of California, Berkeley as a postdoctoral fellow (1983-1984). In 1994, he moved to Okayama University as an associate professor, and became a full professor in 1998. He received the Chemical Society of Japan Award for Young Chemists (1989), the Award of the Society of Synthetic Organic Chemistry, Japan (2008), and the Chemical Society of Japan Award (2014). He has developed several synthetic methods using early transition metals such as chromium, titanium, and tantalum. Current research in his group is aimed toward the use of the complexes of group 7 metals as catalysts in organic synthesis and $\mathrm{C}-\mathrm{H}$ activation initiated by insertion of transition metals into heteroatom-hydrogen bonds.

decade. This short review focuses on recent advancements in the one-pot reaction involving two sequential C-H functionalizations with the formation of two different $\mathrm{C}-\mathrm{X}$ bonds. The graphics in this short review show the initially installed functional group in red, and the secondary introduced group in blue, except for Scheme 1 . Note that the following three types of transformations, which have already been highlighted in previous excellent reviews, ${ }^{5}$ have been omitted: (1) Annulation with multiple bonds existing in one molecule containing alkynes and alkenes (Scheme 1, eqs a and b), (2) Catellani-type coupling reactions using norbornene derivatives as promoters (eq c), and (3) crossdehydrogenative coupling of two different (hetero)aromatic compounds (eq d).

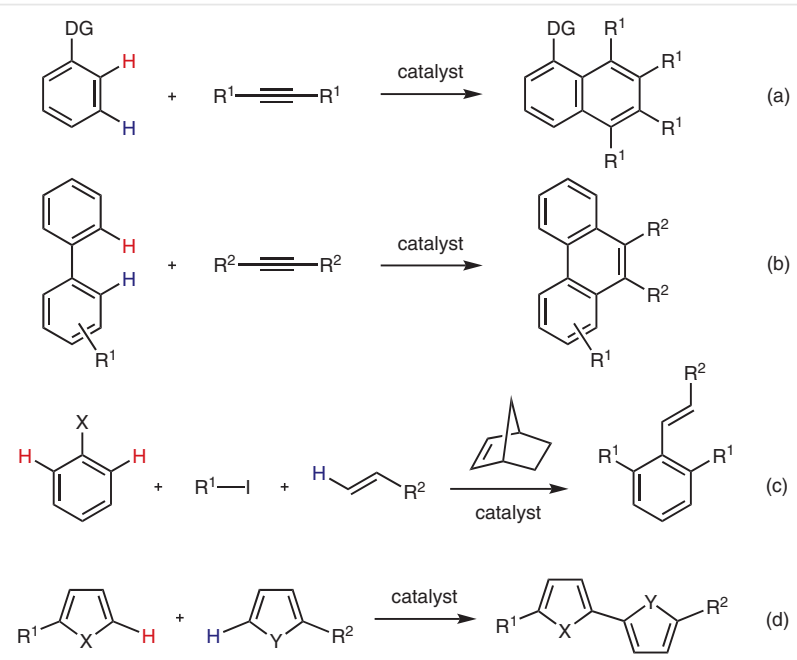

Scheme 1 Catalytic, one-pot, sequential C-H functionalizations not covered in this short review

\section{2 ortho-Selective Functionalization of Two Different C-H Bonds Relative to the Directing Group}

\subsection{Unsymmetrical Difunctionalization with the Introduction of Similar Functional Groups}

A one-pot method for formation of two different C-X bonds via two $\mathrm{C}-\mathrm{H}$ bond cleavages involving rhodium-catalyzed direct alkenylation of a $\mathrm{C}-\mathrm{H}$ bond of 1-phenylpyrazole was reported in 2009 by Miura, Satoh and co-workers. ${ }^{6}$ They demonstrated the one-pot synthesis of unsymmetrically substituted 1,3-dialkenylbenzene derivatives using a pyrazolyl moiety as the directing group. As a typical example, 1-phenylpyrazole was treated with $n$-butyl acrylate in the presence of $\left[\mathrm{Cp}^{*} \mathrm{RhCl}_{2}\right]_{2}$ as the catalyst and $\mathrm{Cu}(\mathrm{OAc})_{2} \cdot \mathrm{H}_{2} \mathrm{O}$ as the oxidant, followed by addition of an excess amount of styrene which, after 2-7 hours, furnished the corresponding meta-dialkenylated pyrazolylarene $\mathbf{1 a}$ in $74 \%$ yield (Scheme 2 ). Changing the order of addition of the two alkenes did not affect the reactivity. Olefination with tert-butyl acrylate required post-treatment with a catalytic amount of $\mathrm{PdCl}_{2}(\mathrm{PhCN})_{2}$ to induce isomerization of the olefinic double bond and furnish the thermodynamically more stable $E$-isomer of $\mathbf{1 b}$. As expected, dialkenylation with two equivalents of the same alkenes also occurred as a side reaction in most cases. However, the current rapid approach to functionalized meta-phenylene vinylene structures enabled the discovery of luminescence of the derivatives having a tert-butyl group, such as $\mathbf{1 b}$, in the solid state. 

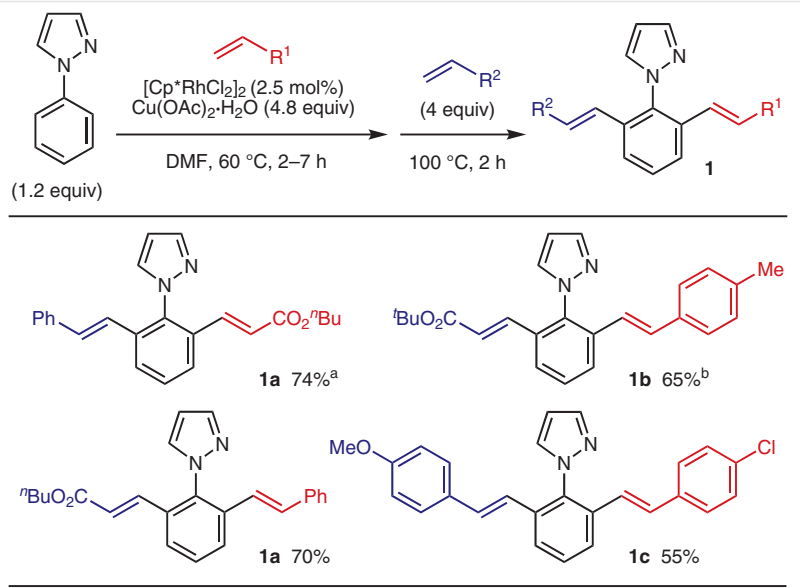

aDetermined by GC. ${ }^{\mathrm{b}}$ After the dialkenylation, the resulting mixture was treated with $\mathrm{PdCl}_{2}(\mathrm{PhCN})_{2}(12 \mathrm{~mol} \%)$ in mesitylene at $150^{\circ} \mathrm{C}$ for $15 \mathrm{~h}$.

Scheme 2 Rhodium-catalyzed one-pot meta-dialkenylation of 1-phenylpyrazoles

Similar sequential ortho-C-H olefination of a 4-methoxyphenol was demonstrated by Lan, You and co-workers using a 2-pyridylmethyl group as a removable directing group (Scheme 3). ${ }^{7,8}$ After initial reaction with $\mathrm{N}, \mathrm{N}$-dimethylacrylamide for 10 hours, $n$-butyl acrylate was added and the reaction stirred for a further 10 hours to yield metadialkenylated $\mathbf{2}$ with an unsymmetrical structure. Both alkenylations presumably proceeded via formation of an unstable seven-membered ring palladacycle intermediate, and the use of Boc-Val-OH [N-(tert-butoxycarbonyl)-L-valine $]^{9}$ as a ligand was essential to accelerate the reaction. The 2-pyridylmethyl group in the product could be removed by $\mathrm{BBr}_{3}$ with the alkenyl double bonds remaining intact. Although the yield was moderate, the reaction provided an efficient approach to meta-dialkenylphenol derivatives, which are important structural motifs in synthetic organic chemistry and materials science.
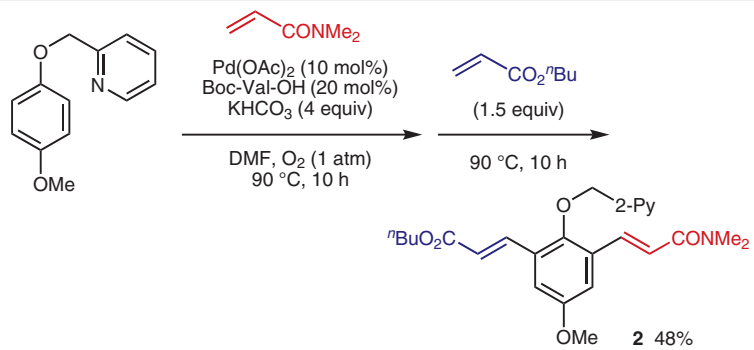

Scheme 3 Palladium-catalyzed one-pot meta-dialkenylation of a 4-methoxyphenol derivative
In 2012, Gevorgyan et al. reported a palladium-catalyzed one-pot sequential acetoxylation and pivaloxylation of $\mathrm{C}-\mathrm{H}$ bonds (Scheme 4). ${ }^{4 \mathrm{C}}$ Using a 2-pyrimidyldiisopropylsilyl group as a directing group, ${ }^{10}$ orthogonally protected resorcinol derivatives $\mathbf{3}$ were obtained in good yield. The acetyl group in the products could be selectively cleaved under basic conditions while keeping the pivaloyl group intact. The 2-pyrimidyldiisopropylsilyl group could also be removed easily or substituted with various other functional groups. ${ }^{\mathrm{i}}$

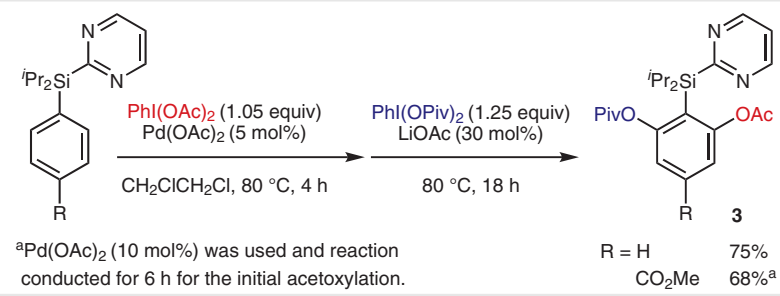

Scheme 4 Palladium-catalyzed, one-pot, sequential acetoxylation and pivaloxylation of $\mathrm{C}-\mathrm{H}$ bonds

In 2017, Zhang, Fan and co-workers reported the synthesis of naphthoquinolizinone derivatives $\mathbf{6}$ via rhodiumcatalyzed carbenoid insertion into two different $\mathrm{C}\left(\mathrm{sp}^{2}\right)-\mathrm{H}$ bonds of 2-aryl-3-cyanopyridine 4 followed by annulation (Scheme 5). ${ }^{11}$ The protocol provided a facile approach to azapyrene skeletons, which possess potentially unique biological and optical properties. Several control experiments revealed that the reaction proceeded via an initial carbene insertion followed by C-cyclization, and a second carbene insertion followed by N-cyclization (Scheme 5). Although the same functional group was introduced at two orthopositions initially, the subsequent double cyclization led to the formation of the unsymmetrical structure.
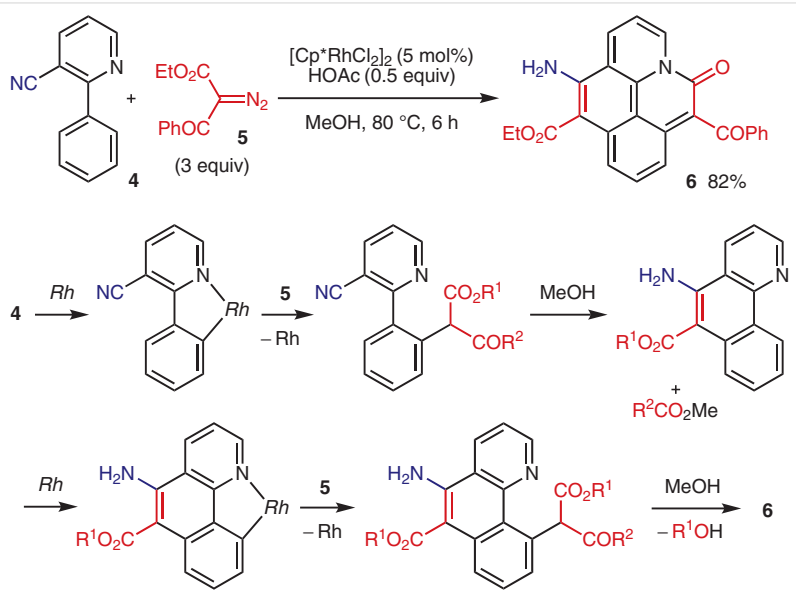

Scheme 5 Rhodium-catalyzed carbenoid insertion into two different $\mathrm{C}\left(\mathrm{sp}^{2}\right)-\mathrm{H}$ bonds of 2-aryl-3-cyanopyridine $\mathbf{4}$ and the proposed reaction mechanism 


\subsection{Unsymmetrical Difunctionalization with the Introduction of Different Functional Groups}

As described so far, catalytic unsymmetrical difunctionalization of two $\mathrm{C}-\mathrm{H}$ bonds existing in one molecule through three-component coupling reactions (i.e., difunctionalization via two sequential intermolecular bond formations) is limited, and most methods have been used to incorporate similar functional groups (see Schemes 13, 15, 22 and 30 for exceptions). Heteroatom-containing directing groups were indispensable for controlling the site selectivity of $\mathrm{C}-\mathrm{H}$ bond activation. However, control of the chemoselectivity to achieve multiple functionalization was difficult, because directing groups are usually highly selective for a certain specific bond formation.

To overcome this limitation, Sahoo et al., in 2016, used benzoic acid derivatives having 0 -tethered double bonds as substrates and demonstrated unsymmetrical difunctionalization with the introduction of two different functional groups. ${ }^{12}$ They envisioned a one-pot sequential reaction involving a rapid intramolecular ortho- $\mathrm{C}-\mathrm{H}$ hydroarylation followed by intermolecular functionalization of a second ortho- $\mathrm{C}-\mathrm{H}$ bond. The use of a methylphenylsulfoximidoyl (MPS) moiety as a directing group ${ }^{13}$ and the combination of $\left[\mathrm{RuCl}_{2}(p \text {-cymene })\right]_{2}$ with $\mathrm{AgSbF}_{6}$ as the catalyst were essential to realize the expected transformation. Differently functionalized dihydrobenzofuran derivatives $\mathbf{7 a}$ and $\mathbf{7 b}$ were obtained by hydroarylation/amidation cascades with sulfonylazides, and the reaction with phenyl vinyl sulfone through intra- and intermolecular sequential hydroarylations introduced an alkyl group at the 5-position leading to 7c (Scheme 6). In contrast, the reaction with ethyl acrylate selectively yielded the alkenylated product $\mathbf{7 d}$. The substrate scope could be expanded to $\mathrm{N}$-tethered olefins to furnish highly substituted indoline derivatives $7 \mathbf{e}$ and $\mathbf{7 f}$ in moderate yields. Because the initial intramolecular cyclization occurred at low temperature with a high functional group tolerance, the overall reaction could be performed in a single operation simply by raising the temperature for the second coupling reaction. The sequential intramolecular hydroarylation with two different double bonds of alkenes was also demonstrated as an unsymmetrical difunctionalization under mild conditions (Scheme 6, eq 1).

Properly functionalized phenol derivatives are not only common structures observed in many pharmaceuticals and functional materials but are also useful building blocks in organic synthesis. However, conventional approaches toward their synthesis often require multi-step transformations using reactive organolithium reagents and harsh conditions, which limits the number of allowable functional group. In 2018, Zhou et al. reported the rhodium-catalyzed sequential ortho- $\mathrm{C}-\mathrm{H}$ alkylation/amidation of $\mathrm{N}$-phenoxyacetamides $\mathbf{9}$ leading to unsymmetrically substituted phenol derivatives 10 (Scheme 7). ${ }^{14}$
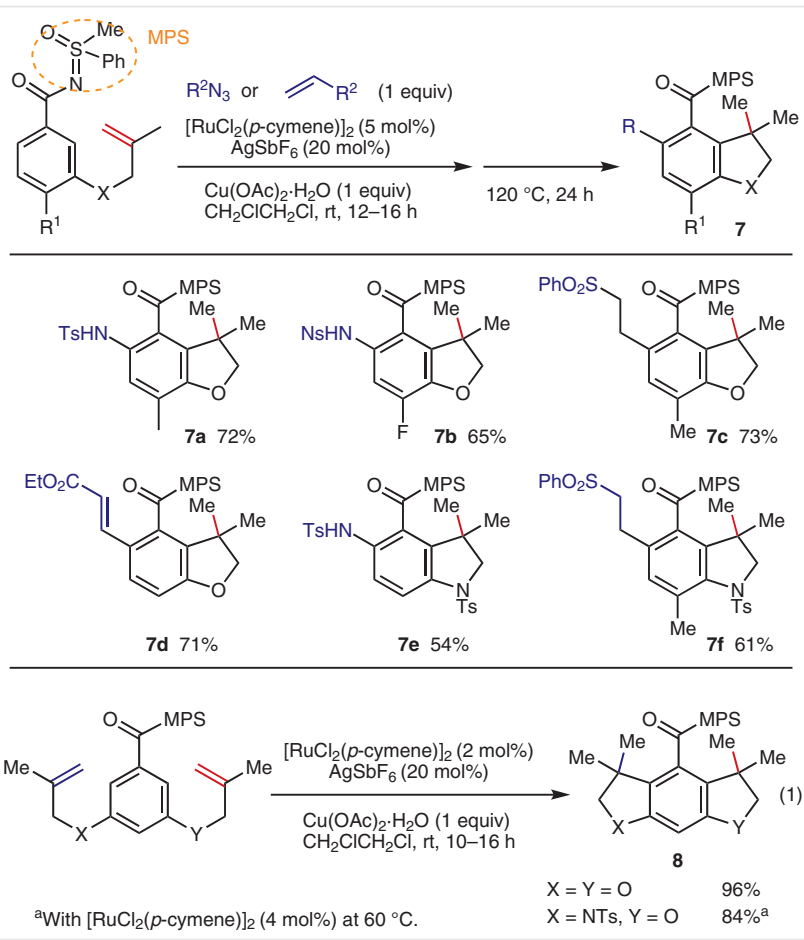

Scheme 6 Ruthenium-catalyzed one-pot hydroarylation-amidation/alkylation/alkenylation of aroylmethylphenyl sulfoximines
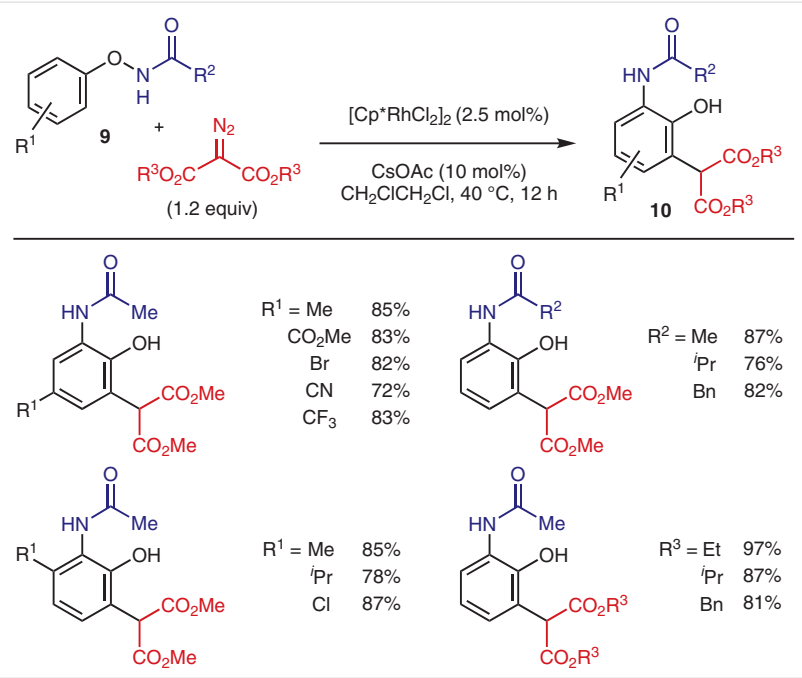

Scheme 7 Rhodium-catalyzed one-pot alkylation/amidation of $\mathrm{N}$-phenoxyacetamides

The acetylamino group worked as an oxidizing directing group, ${ }^{15}$ which not only facilitated site-selective alkylation with diazomalonate but also generated an acetylamino group in the migration reaction step without using any oxidants under mild conditions. Diverse functional groups, such as methoxycarbonyl, chloro, and cyano groups, were compatible, and even bromo groups tolerated the reaction conditions. When using phenol derivatives having substitu- 
ents at meta-positions, alkylation occurred selectively at the sterically less hindered position, and 1,2,3,4-tetrasubstituted benzenes were formed exclusively as a single product after the overall reaction.

Several mechanistic studies revealed that the $\mathrm{C}\left(\mathrm{sp}^{2}\right)-\mathrm{H}$ bond cleavage was involved in the rate-determining step, and a shift of an acetylamino group occurred intramolecularly. Because the use of $\mathrm{N}$-(2-hydroxyphenyl)acetamide as a precursor did not provide the desired product, intermolecular $\mathrm{C}-\mathrm{H}$ alkylation with diazo compounds occurred before the intramolecular 1,2-shift of the acetylamino group (Scheme 8).

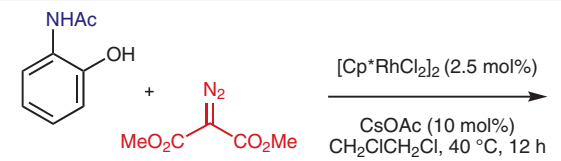
(1.2 equiv)

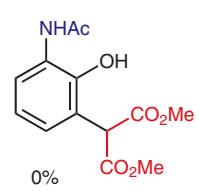

$0 \%$
Scheme 8 Mechanistic insights

Based on these results, the mechanism shown in Scheme 9 was proposed. First, ligand exchange of [Cp*Rh$\left.\mathrm{Cl}_{2}\right]_{2}$ with $\mathrm{CsOAc}$ provided $\mathrm{Cp} * \mathrm{Rh}(\mathrm{OAc})_{2}(\mathbf{A})$, which was then converted into rhodacycle intermediate $\mathbf{B}$ by reaction with $N$-phenoxyacetamide 9. Coordination of the diazo compound to the rhodium center, followed by 1,2-migratory insertion of the aryl group provided the six-membered ring intermediate $\mathbf{C}$. Next, $\mathrm{Rh}(\mathrm{V})$ nitrenoid intermediate $\mathbf{D}$ was formed via oxidative addition of $\mathrm{Rh}(\mathrm{III})$ into the $\mathrm{N}-\mathrm{O}$ bond. Subsequent protonation leading to acyclic $\mathbf{E}$, and then intramolecular electrophilic nitrenoid addition furnished dearomatized intermediate F. Finally, product $\mathbf{1 0}$ was formed by sequential protonation of $\mathbf{F}$ and rearomatization along with the regeneration of $\mathbf{A}$. In contrast to the aforementioned work of Sahoo (see Scheme 6), ${ }^{12}$ intermolecular $\mathrm{C}-\mathrm{H}$ functionalization occurred prior to intramolecular $\mathrm{C}-\mathrm{H}$ functionalization due to the slow generation of nitrenoid intermediate $\mathbf{D}$.

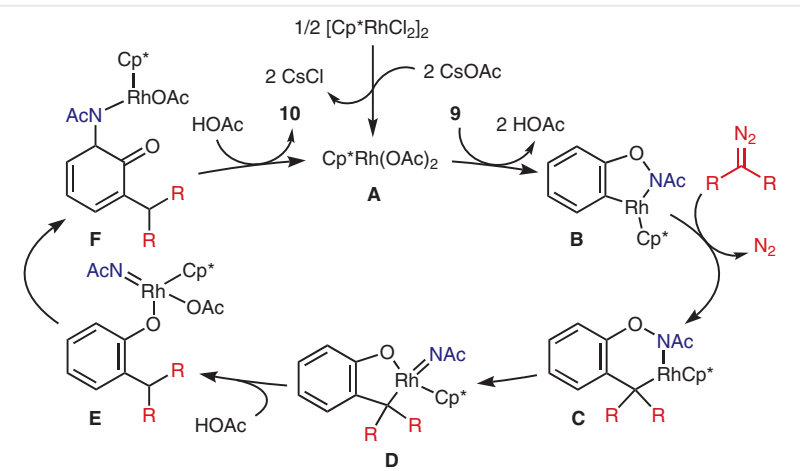

Scheme 9 Proposed reaction mechanism
This protocol can be also applied to the transformation of biologically active molecules such as estrone derivatives (Scheme 10). The first alkylation again occurred site selectively at the sterically less hindered position. This result confirmed that the current unsymmetrical ortho $\mathrm{C}-\mathrm{H}$ functionalization provided a reliable shortcut to highly substituted phenol derivatives, which are inaccessible by conventional synthetic methods.

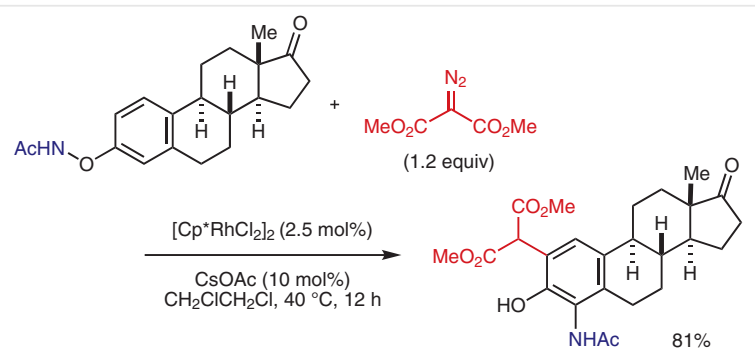

Scheme 10 Transformation of a biologically active estrone derivative

Recently, a similar strategy was described by Song et al. involving a palladium-catalyzed one-pot alkenylation (Heck reaction)/sulfenylation of aryl thiocarbamates (Scheme 11). ${ }^{16}$ For this difunctionalization, intermolecular alkenylation proceeded rapidly during the slow $\mathrm{C}-\mathrm{S}$ bond formation by reductive elimination of a $\mathrm{C}_{\mathrm{Ar}} \mathrm{Pd}-\mathrm{S}$ species. Diverse trior tetrasubstituted benzenes $\mathbf{1 1}$ were obtained using a catalytic amount of $\mathrm{Pd}(\mathrm{OAc})_{2}$ and benzoquinone as the oxidant in an acidic medium. Styrene as well as acrylate esters could be used as coupling partners. When aryl thiocarbamates possessing two unsymmetrical meta $\mathrm{C}-\mathrm{H}$ bonds were used, the initial intermolecular alkenylation occurred selectively at the sterically less hindered position.
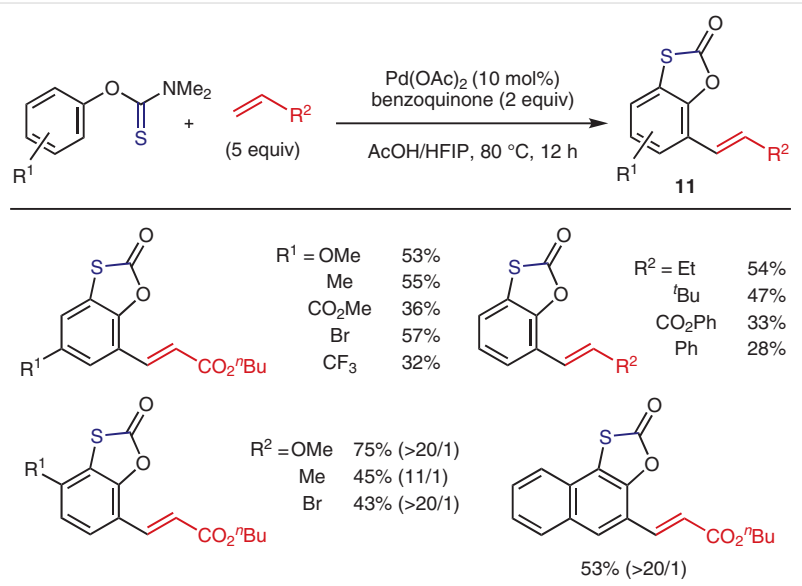

Regioselectivity is shown in parentheses.

Scheme 11 Palladium-catalyzed one-pot alkenylation/sulfenylation of aryl thiocarbamates 
The resulting products could be transformed into tetrasubstituted phenol derivatives via ring opening of the oxathiol-2-one ring triggered by amination or saponification (Scheme 12). Although the use of an excess amount of the olefin was required to control the reactivity, excellent functional group compatibility and site selectivity proved the usefulness of this one-pot difunctionalization protocol.

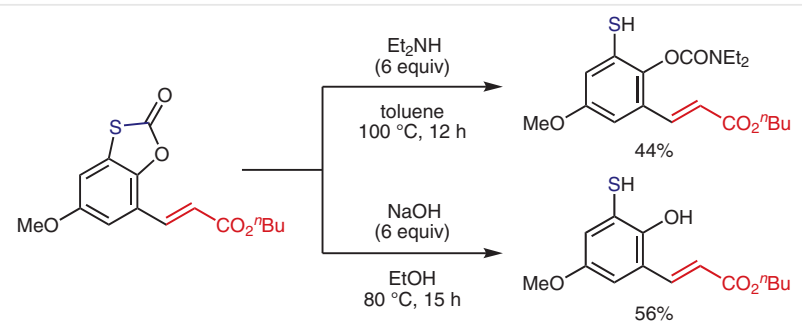

Scheme 12 Transformation of product 11

\section{3 ortho-Selective Unsymmetrical Difunctional- ization Promoted by Two Different Directing Groups Appearing During the Progress of the Reaction}

One-pot difunctionalization in a three-component coupling reaction was achieved by Qian, Dong and co-workers in $2014 .{ }^{17}$ The rhodacycle intermediate generated from the reaction of $\mathrm{N}$-sulfonyl ketimines $\mathbf{1 2}$ and internal alkynes was trapped by different aldehydes leading to polycyclic products 13 (Scheme 13). Functional groups, including iodide, nitro, and alkoxycarbonyl, were all well-tolerated, and the substrate scope was broad. The addition of di-tert-butyl dicarbonate $\left[(\mathrm{Boc})_{2} \mathrm{O}\right]$ was indispensable, with the twocomponent coupling product 14a being obtained as the major product without $(\mathrm{Boc})_{2} \mathrm{O}$ (Scheme 13). Thus, the reaction mechanism shown in Scheme 14 is most plausible, which involves: (1) imino-group-directed ortho-C-H alkenylation leading to seven-membered ring rhodacycle intermediate G, (2) intramolecular cyclization via insertion of the alkenylrhodium species into the $\mathrm{C}=\mathrm{N}$ bond, (3) aminogroup-assisted $\mathrm{C}-\mathrm{H}$ activation leading to azarhodacycle $\mathbf{H}$ followed by insertion of a formyl group, and (4) final dehydrogenative cyclization assisted by $(\mathrm{Boc})_{2} \mathrm{O}$, which promoted the leaving ability of the $\mathrm{OH}$ group, leading to $\mathbf{1 3}$. Although directing groups are usually highly specific for a certain $\mathrm{C}-\mathrm{H}$ bond, they changed with the progress of the reaction in this difunctionalization.

Adapting a similar strategy, Sahoo et al. reported unsymmetrical annulation via the activation of two $\mathrm{C}\left(\mathrm{sp}^{2}\right)-\mathrm{H}$ bonds. ${ }^{18}$ By controlling the $\mathrm{pH}$ of the reaction medium, two $\mathrm{C}-\mathrm{C}$ and two $\mathrm{C}-\mathrm{N}$ bonds were formed efficiently in a single operation. The reaction proceeded with broad substrate scope and good functional group tolerance, providing structurally complicated spiroisoquinolones $\mathbf{1 5}$ from readily accessible starting materials (Scheme 15). Based on the mechanistic studies, the following three key steps were
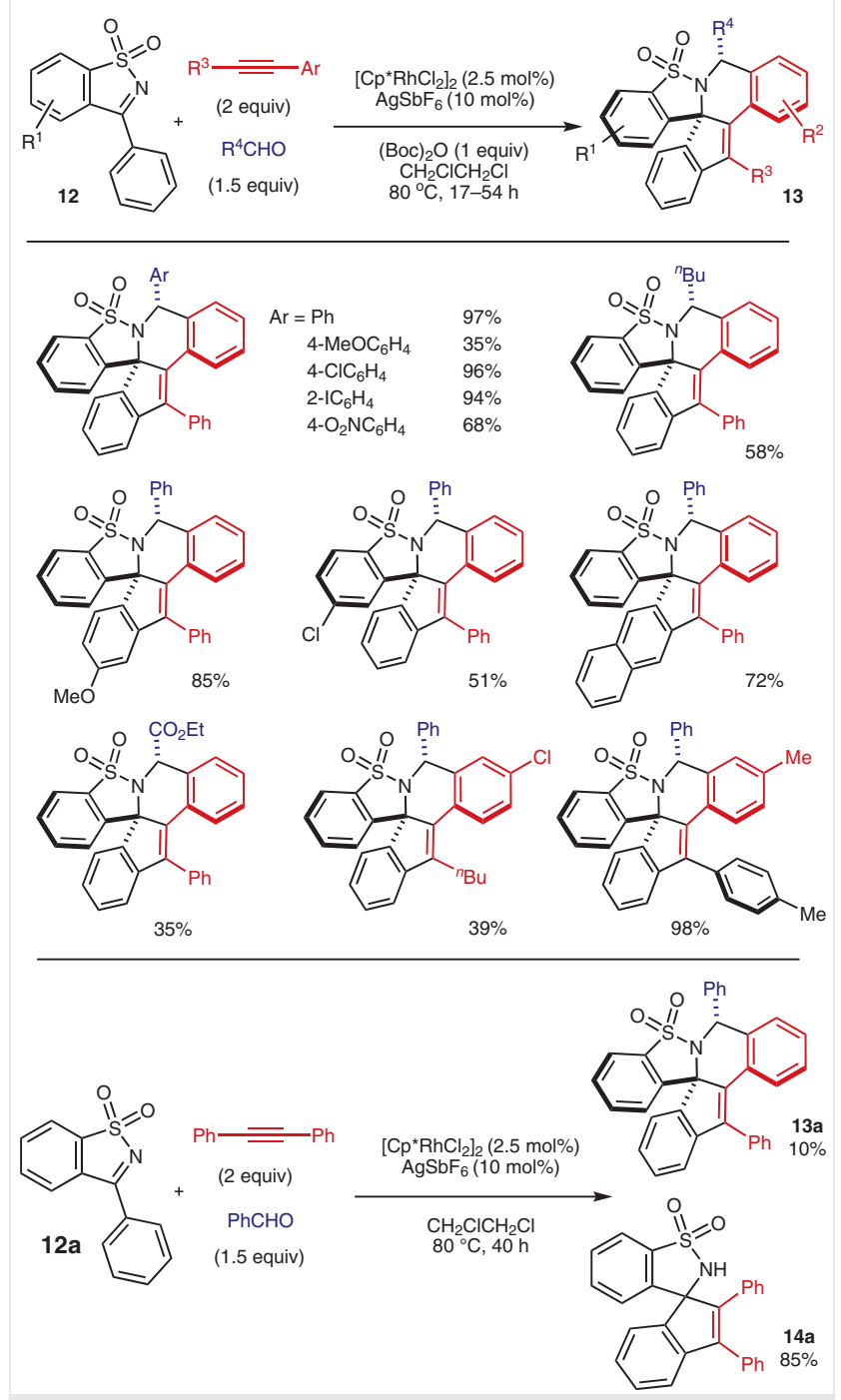

Scheme 13 Rhodium-catalyzed three-component coupling reaction of $\mathrm{N}$-sulfonyl ketimines, internal alkynes and aldehydes

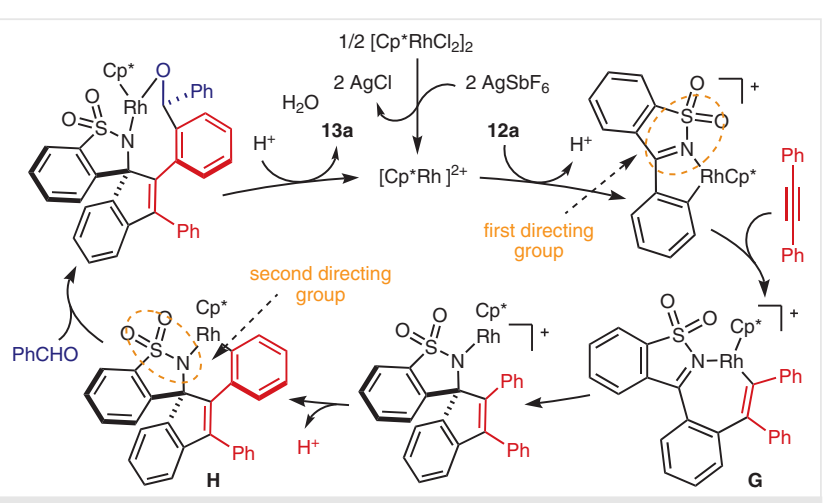

Scheme 14 Plausible reaction mechanism 
postulated in the current transformation (Scheme 16): (1) Initial annulation of the proximal $\mathrm{C}-\mathrm{H}$ bond of the MPS group with alkynes under acidic conditions, (2) formation of an isoquinolone or pyridone intermediate along with regeneration of the ruthenium active species; the MPS group acted as an internal oxidant to promote this regeneration step, ${ }^{15}$ and (3) the second $\mathrm{C}-\mathrm{H}$ bond annulation with quinone, which was assisted by the coordination of a ruthenium complex to the $\mathrm{N}-\mathrm{H}$ bond of isoquinolone or pyridone, under basic conditions. $\mathrm{Cu}(\mathrm{OAc})_{2}$ oxidized the $\mathrm{Ru}(0)$ species back to the reactive $\mathrm{Ru}(\mathrm{II})$ species in the second annulation step.
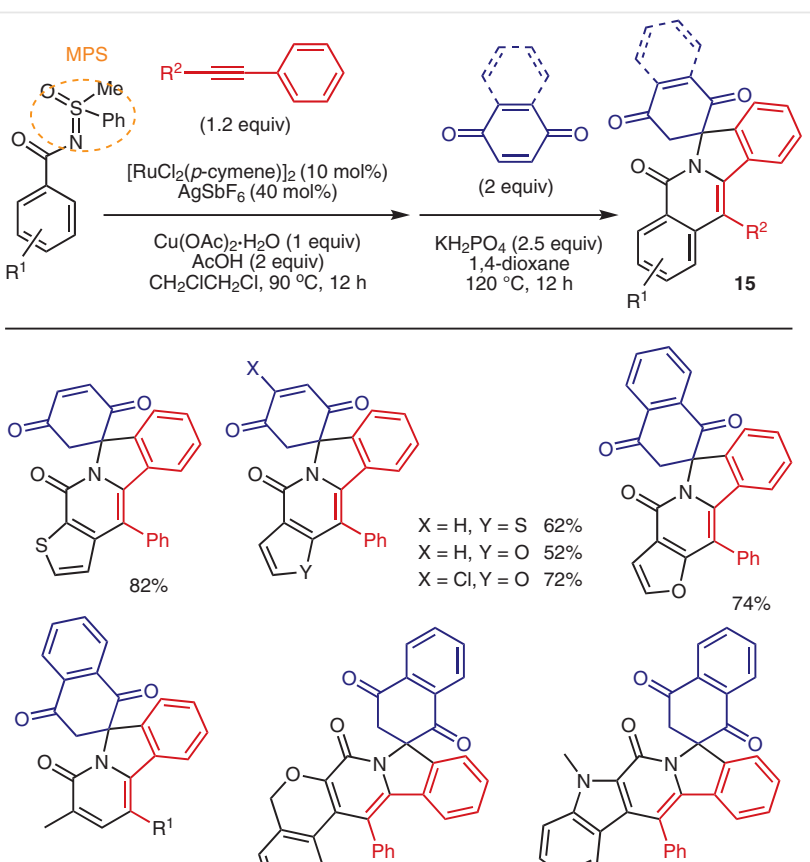

$\mathrm{R}^{1}=\mathrm{Ph} 62 \%$
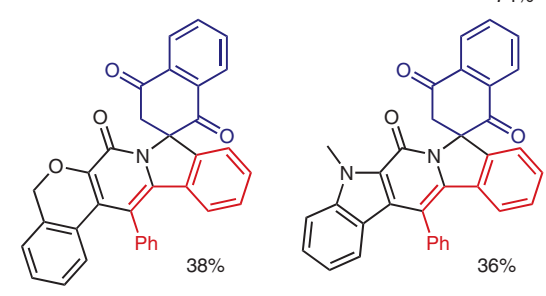

Scheme 15 Ruthenium-catalyzed unsymmetrical annulation with alkynes and quinones leading to spiroisoquinolones
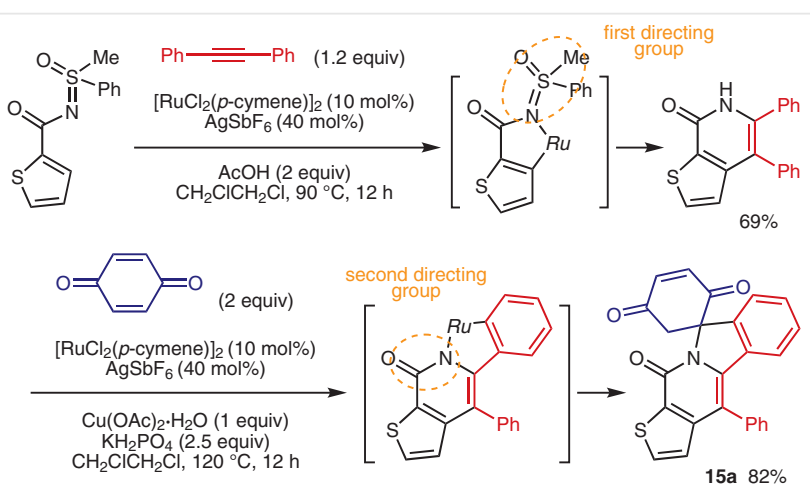

Scheme 16 Stepwise annulation via two different $\mathrm{C}-\mathrm{H}$ bond activations
A unique skeletal reconstruction of benzyl aryl sulfoxides into dibenzothiophene-1-carbaldehydes $\mathbf{1 6}$ through unsymmetrical difunctionalization of two $\mathrm{C}-\mathrm{H}$ bonds was reported by Anthonchick in 2011. ${ }^{19}$ Although the yields were moderate, variously substituted dibenzothiophene derivatives having unsymmetrical structures were obtained from simple precursors through the formal abstraction of four hydrogen atoms (Scheme 17). The transformation appears complicated, but the following pathway supported by several mechanistic studies was proposed (Scheme 18): (1) Formation of cyclic sulfoxide $\mathbf{J}$ promoted by sulfoxidegroup-assisted regioselective direct arylation of the $\mathrm{C}-\mathrm{H}$ bond, (2) Pummerer rearrangement leading to mercaptoaldehyde $\mathbf{K}$, and (3) sulfur-group-directed C-S bond formation. Addition of $p$-fluoroiodobenzene and AgOAc was crucial for decreasing the catalyst loading of $\mathrm{PdCl}_{2}$. In the absence of $p$-fluoroiodobenzene, stoichiometric amounts of a palladium complex were required. This iodoarene was thought to play a key role in generating mononuclear $\mathrm{Pd}(\mathrm{IV})$ species, which then underwent reductive elimination along with $\mathrm{C}-\mathrm{H}$ activation to produce palladacycle $\mathbf{I}$. Interestingly, neither Pummerer rearrangement of the starting benzyl aryl sulfoxides nor arylation of several palladacycle intermediates with iodoarene was observed. Similar to the transformations shown in Schemes 13 and 15, two different directing groups appeared during the progress of the reaction, and promoted the current strictly defined reaction sequence.
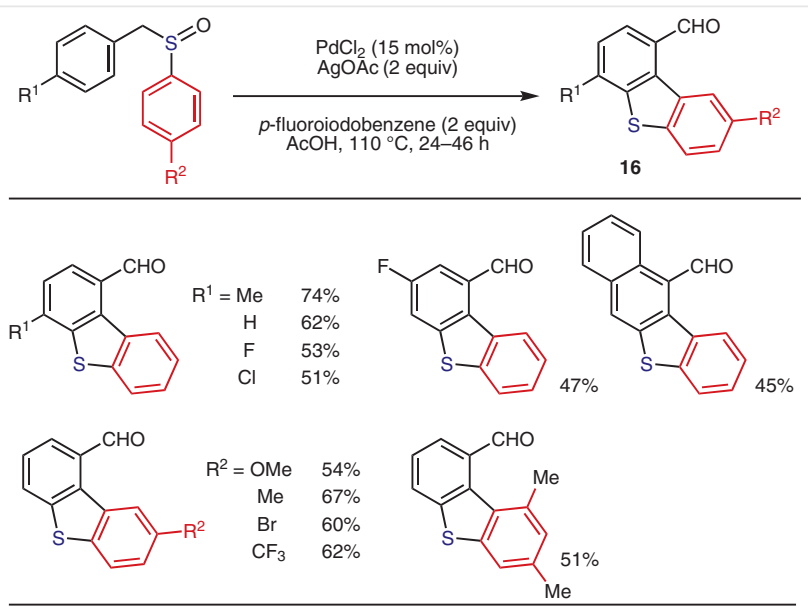

Scheme 17 Palladium-catalyzed regioselective intramolecular arylation and sulfenylation of $\mathrm{C}-\mathrm{H}$ bonds leading to dibenzothiophene-1carbaldehydes 


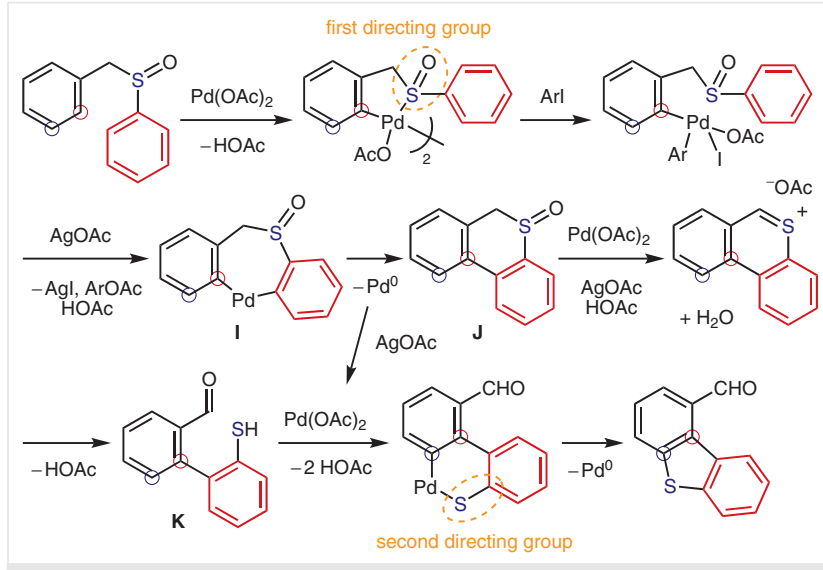

Scheme 18 Plausible reaction mechanism

\section{3 ortho/meta-Selective C-H Bond Difunc- tionalization Relative to the Directing Group}

In 2017, Li et al. reported a conceptually different onepot difunctionalization based on ortho/meta $\mathrm{C}-\mathrm{H}$ bond cleavage. ${ }^{20,21}$ The use of $\left[\mathrm{RuCl}_{2}(p \text {-cymene })\right]_{2}$ without ligands and bases allowed ortho-chlorination and meta-sulfonation of 2-phenoxypyridines $\mathbf{1 7}$ with arylsulfonyl chlorides. The typical promoter for meta-sulfonation of 2-phenylpyridines, ${ }^{22} \mathrm{~K}_{2} \mathrm{CO}_{3}$, did not improve the efficiency of the current ortho/meta-difunctionalization. The choice of solvent appears to be important, and the desired difunctionalized products 18 were obtained only in xylene or toluene. Although substituents at the meta-position of the 2-pyridyloxy group and strongly electron-withdrawing substituents shut down the reaction, site-selective incorporation of chloro and sulfonyl groups was observed in a variety of 2aryloxypyridines and pyrimidines (Scheme 19). A 2-pyridyl group in the product could be removed to release the free phenolic hydroxy group by treatment with MeOTf followed by MeONa.

Insight into the reaction mechanism was obtained from the following reactions. First, the desired difunctionalized product 18a was obtained from 2-phenoxypyridine 19 having a $p$-tosyl group at the meta-position, indicating that chlorination occurred after sulfonation (Scheme 20, a). Second, the cyclic six-membered ruthenacycle intermediate 20 reacted with $p$-tosyl chloride to give the expected product 18a, quantitatively (Scheme 20, b). Third, the radical scavenger TEMPO completely quenched the reaction (Scheme 20, c).

Supported by the experimental results, a plausible reaction pathway involving complex 20a is shown in Scheme 21. First, the para position of the $\mathrm{Ru}-\mathrm{C}$ bond of ruthenacycle intermediate $\mathbf{2 0 a}$, generated via ortho $\mathrm{C}-\mathrm{H}$ activation of 2-phenoxypyridine 17a, was attacked by $p$-tosyl chloride to form intermediate $\mathbf{L}^{2}{ }^{2 \mathrm{~b}}$ A strong para-directing effect of the $\mathrm{Ru}-\mathrm{C} \sigma$-bond determined the site-selectivity in this step. ${ }^{22}$
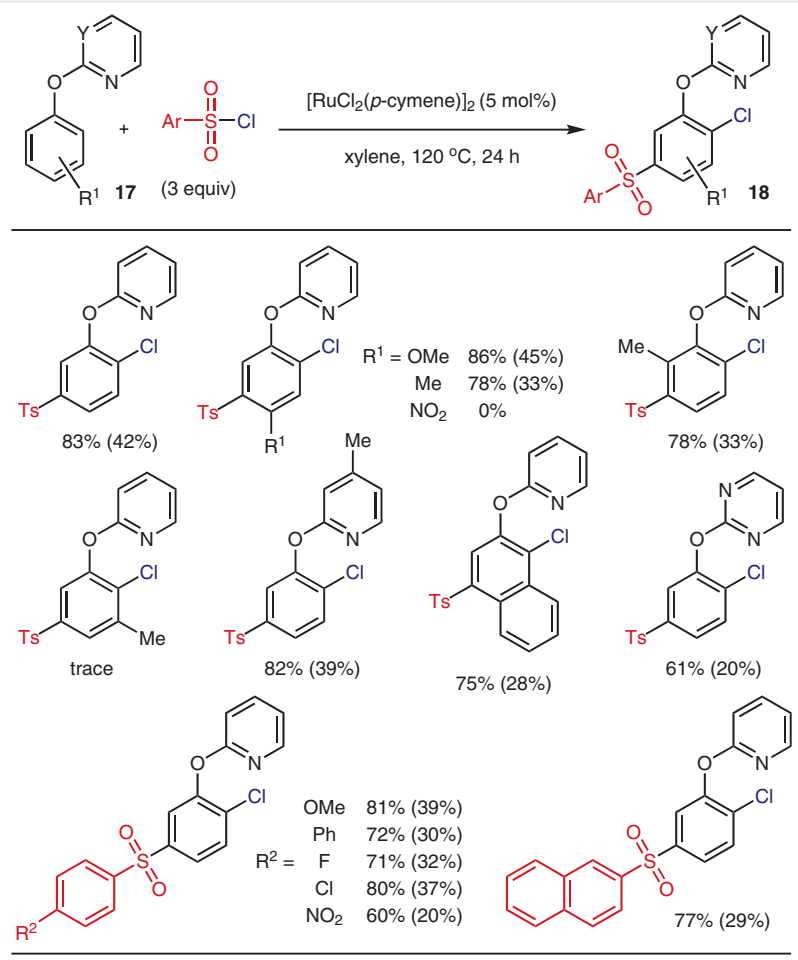

Isolated yields based on recovered starting materials were reported in ref 20 . Values in parentheses are isolated yields based on starting materials employed, which were calculated from the data in the Supporting Information of ref 20.

Scheme 19 Ruthenium-catalyzed one-pot ortho-chlorination and meta-sulfonation of 2-phenoxypyri(mi)dines

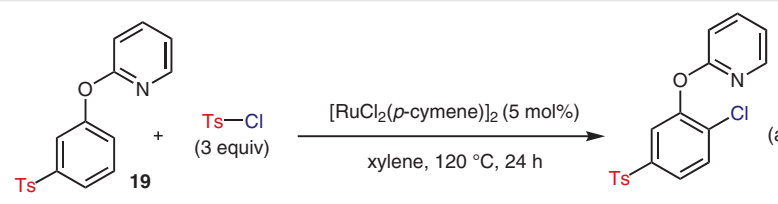

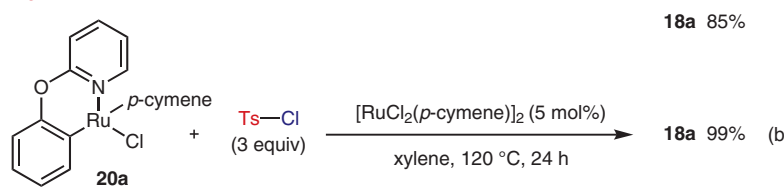

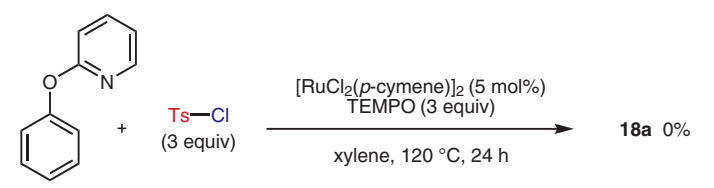

Scheme 20 Mechanistic studies

Oxidative addition of $p$-tosyl chloride gave $\mathrm{Ru}(\mathrm{IV})$ intermediate $\mathbf{M}$, which then underwent reductive elimination to provide 18a and ruthenium complex $\mathbf{N}$. Although the details of the regeneration of $\mathbf{2 0 a}$ by the reaction of $\mathbf{N}$ with another molecule of 17a was not described, the authors detected (chloromethyl)methylbenzene and $p$-tolyl-4-methylbenzenesulfonothioate as side products under standard reaction conditions by GC-MS analysis. Thus, they concluded that $p$-tosyl chloride acted not only as a sulfonation and 
chlorination source, but also as an oxidant to regenerate 20a. Although the reaction efficiency was not high enough for practical use, this work demonstrated the novel strategy of unsymmetrical difunctionalization with the introduction of two different functional groups.

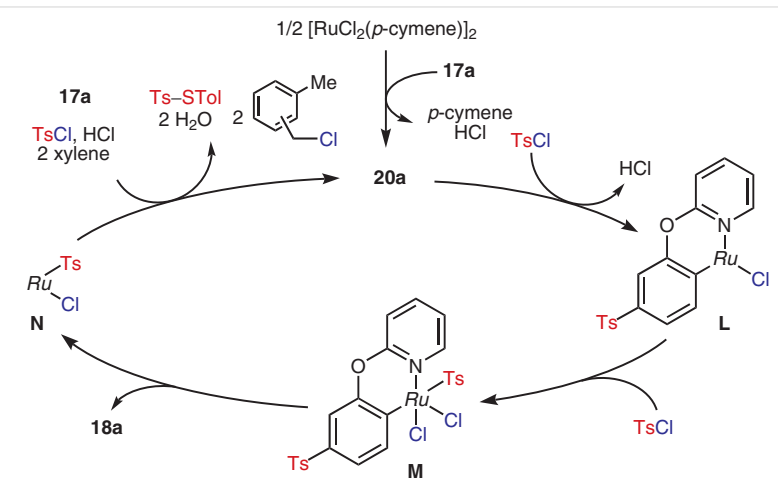

Scheme 21 Proposed reaction mechanism [Ru = Ru(p-cymene)]

At about the same time, Ackermann et al. developed a three-component coupling reaction of 2-aryloxazolines, sec-alkyl halides (2-bromoalkanoates), and aryl halides. ${ }^{23}$ ortho-Arylation and meta-alkylation occurred efficiently with complete site selectivity in this reaction. First, they reported that the combination of a ruthenium(II) biscarboxylate complex $\left[\mathrm{Ru}(\mathrm{OCOR})_{2}(p \text {-cymene })\right]_{2}$ with $\mathrm{PPh}_{3}$ displayed excellent catalytic performance toward alkylation of meta $\mathrm{C}-\mathrm{H}$ bonds with sec-alkyl halides. ${ }^{24}$ The yield was reduced to less than $5 \%$ using the typical $\left[\mathrm{RuCl}_{2}(p \text {-cymene })\right]_{2}$ as the catalyst. In contrast to Li's work using 2-phenoxypyridines as substrates (see Scheme 19), formation of ortho-halogenated products was not observed. Next, the simple addition of aryl bromides after completion of the initial meta-alkylation was found to provide variously substituted 2-aryloxazolines 21 in good yields. [Ru(OCOMes $)_{2}(p$-cymene $\left.)\right]_{2}$ was used for aryloxazolines (Scheme 22), while a similar ruthenium complex containing a bulkier adamantyl group substituted ligand was chosen for other arylheterocycles, such as 1 -aryl-1H-pyrazoles and 6-phenyl-7H-purines (Scheme 23).

Several control experiments confirmed that the reaction occurred via reversible $\mathrm{C}-\mathrm{H}$ bond cleavage exclusively at the ortho-position (Scheme 24, a), and the stereochemistry of the sec-alkyl bromide was not preserved during meta-alkylation (Scheme 24, b). These observations could be rationalized by considering the mechanism of the typical ruthenium-catalyzed meta-alkylation, which involved attack of the radical species generated from sec-alkyl halides at the para-position of the $\mathrm{Ru}-\mathrm{C} \sigma$-bond of the ruthenacycle intermediate. ${ }^{22}$

The good reactivity and high functional group tolerance observed in the initial alkylation allowed sequential ortho/meta-difunctionalization in a single operation simply
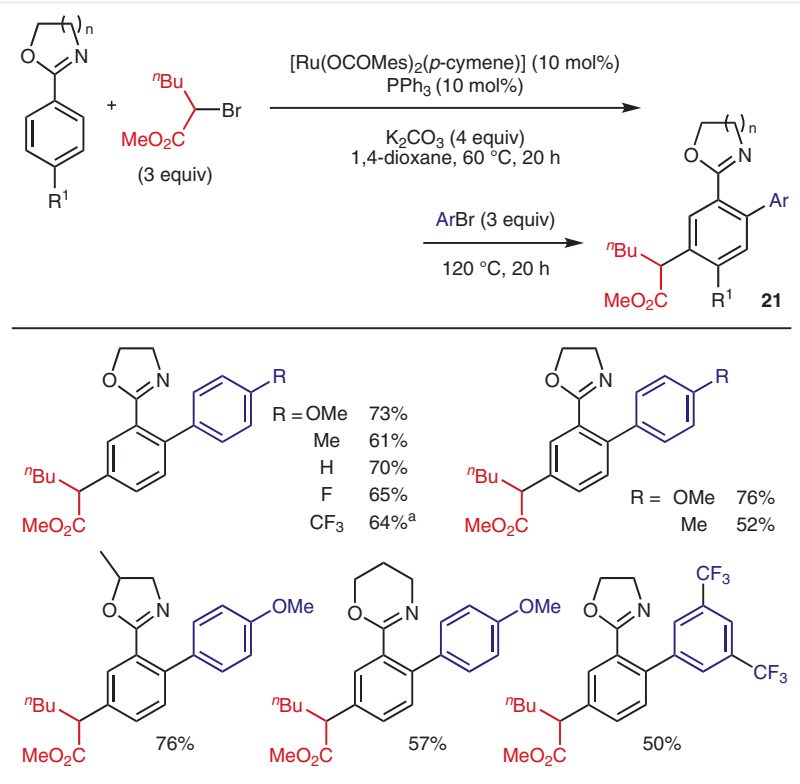

a $4-\mathrm{F}_{3} \mathrm{CC}_{6} \mathrm{H}_{4} \mathrm{I}$ was used as a coupling partner.

Scheme 22 Sequential meta-alkylation/ortho-arylation of aryloxazolines
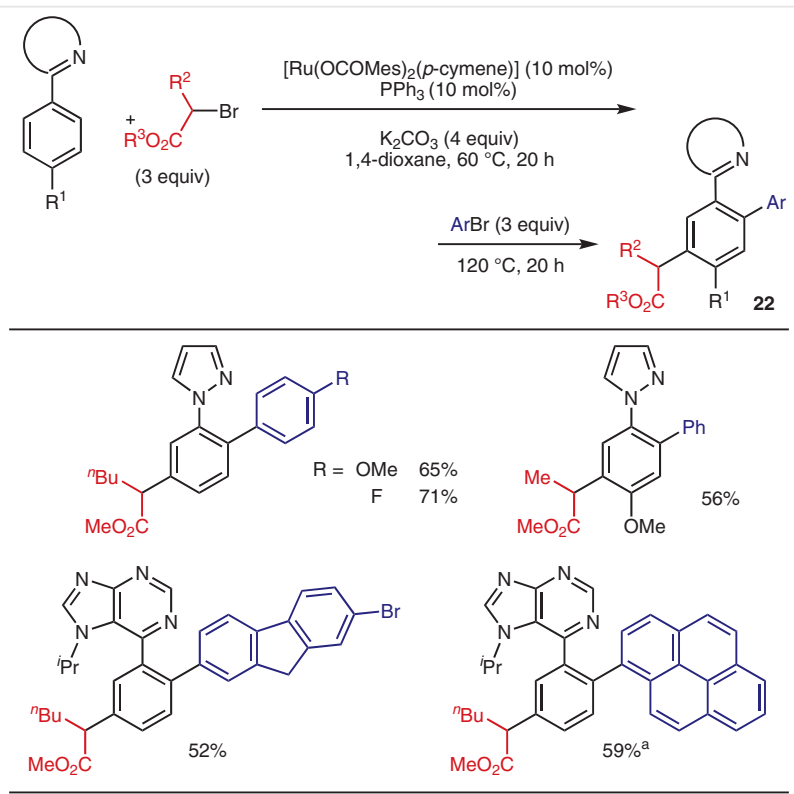

a 1-(4-Bromophenyl)pyrene (2 equiv) was used.

Scheme 23 Sequential meta-alkylation/ortho-arylation of aryl-pyrazoles and -purines

by raising the temperature for the second arylation (Scheme 25). Most of the directing groups used in this study could be easily converted into various carbonyl groups, and the current difunctionalization technique provided a robust and straightforward approach to highly functionalized benzene derivatives. 
<smiles>c1ccc(C2=NCCO2)cc1</smiles>

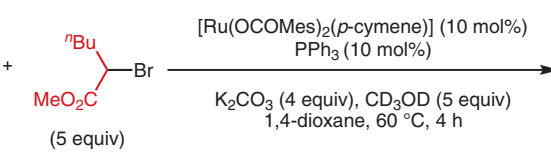

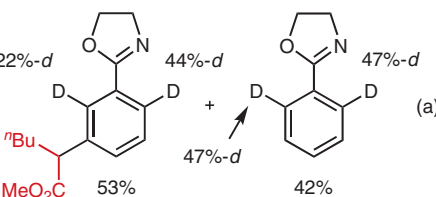<smiles>c1ccc(C2=NCCO2)cc1</smiles><smiles>O=C1OC[C@@H](Br)[C@H]1Br</smiles>

$\left[\mathrm{Ru}(\mathrm{OCOMes})_{2}(p\right.$-cymene) $](10 \mathrm{~mol} \%)$ $\frac{\underset{\mathrm{PPh}_{3}(10 \mathrm{~mol} \%)}{\mathrm{K}_{2} \mathrm{CO}_{3}(2 \text { equiv) }}}{1,4 \text {-dioxane, } 60^{\circ} \mathrm{C}, 20 \mathrm{~h}}$ (0.77 equiv)

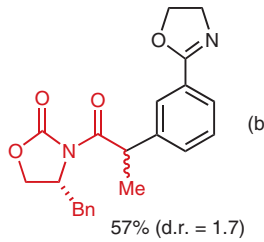

Scheme 24 Control experiments

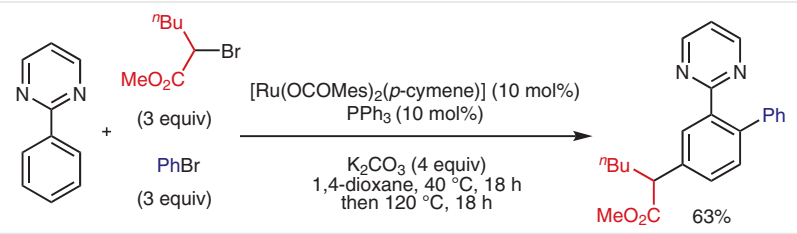

Scheme 25 Sequential ortho/meta-difunctionalization in a single operation

\section{Sequential Difunctionalization of Fused Aromatic Compounds and Heterocycles}

Unsymmetrical difunctionalization of fused aromatic compounds, which have multiple potentially reactive $\mathrm{C}-\mathrm{H}$ bonds with close bonding energies, is difficult. A unique example is the catalytic chloroamination of indoles with $\mathrm{N}$-chloro- $\mathrm{N}$,4-dimethylbenzenesulfonamide (TsMeNCl) reported by Liu et al. in $2011 .{ }^{25 a, 26}$ Using a combination of palladium and copper as the catalyst, the difunctionalization proceeded efficiently under mild conditions to yield 2-amino-3-chloroindoles 23 without producing other regioisomers (Scheme 26). The nature of the substituents on the benzene ring of the indoles affected the reactivity, with electron-withdrawing groups decreasing the reactivity. Pyrrole also afforded a chloro-aminated product under the same reaction conditions. Interestingly, replacing the $\mathrm{CuCl}$ complex with $\mathrm{Cu}(\mathrm{acac})_{2} / 2,2^{\prime}$-bipyridine and decreasing the amount of $\mathrm{TsMeNCl}$ (1.8 equiv) gave the 2-aminoindole instead of the chloro-aminated product. However, no reaction insights gained using the conditions shown in Scheme 26, including the order of functionalization as well as the role of palladium and copper catalysts, were described. The metal-free chloroamination of indoles with sulfonamides and $\mathrm{NaClO}$ has also been reported. ${ }^{26 \mathrm{~b}}$
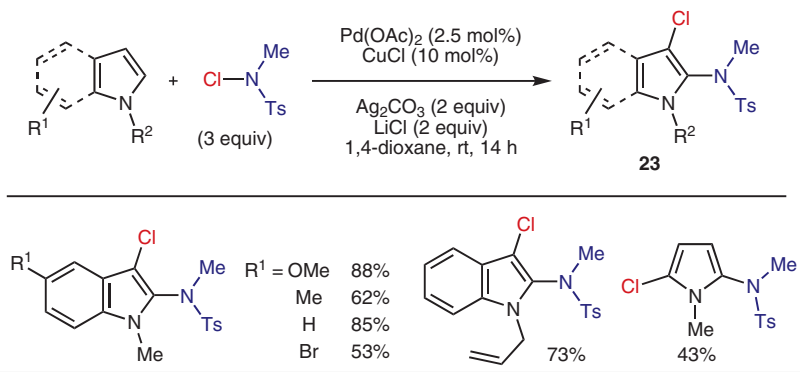

Scheme 26 Palladium/copper-catalyzed site-selective chloroamination of indoles and a pyrrole

One-pot $\mathrm{C}-\mathrm{H}$ bond difunctionalization of indoles was also achieved using a stoichiometric amount of copper salts. Nicholas reported the bromoamination of indoles with oxime esters and $\mathrm{CuBr} \cdot \mathrm{SMe}_{2}$ (Scheme 27, a). ${ }^{25 \mathrm{c}}$ Attempted catalytic variants of this reaction using $\mathrm{NaBr}, \mathrm{LiBr}$, and ${ }^{n} \mathrm{Bu}_{4} \mathrm{NBr}$ as the external bromide source failed, instead giving 3-bromo- $N$-methylindole exclusively. ${ }^{27}$ Because this brominated indole was obtained as a side product, and not converted into the expected bromo-aminated product $\mathbf{2 4}$ under the conditions shown in Scheme 27, a, the yield of the difunctionalized products in the current method were moderate to low. The authors proposed a mechanism involving electrophilic addition of a $(\mathrm{AcO}) \mathrm{Cu}{ }^{\text {III }} \mathrm{Br}\left(\mathrm{N}=\mathrm{CPh}_{2}\right)$ species at the 3-position of the indole ring followed by installation of a nucleophilic imino unit at the 2-position prior to reductive elimination of the copper species to form the $\mathrm{C}$ $\mathrm{Br}$ bond. Recently, copper-mediated one-pot iodination and nitration was demonstrated by Jiang et al. (Scheme 27, b). ${ }^{25 \mathrm{~d}}$ ${ }^{t} \mathrm{BuONO}$ and $\mathrm{Cul}$ were used as nitrating and iodinating reagents, respectively. Several control experiments revealed that iodination proceeded even at room temperature prior to the nitration, and nitration occurred with $\mathrm{NO}_{2}$ radicals generated from thermal decomposition and oxidation of ${ }^{t} \mathrm{BuONO}$. Although the protocol required directing groups to promote nitration at the 2-position, they could be easily cleaved by methylation and alcoholysis. 


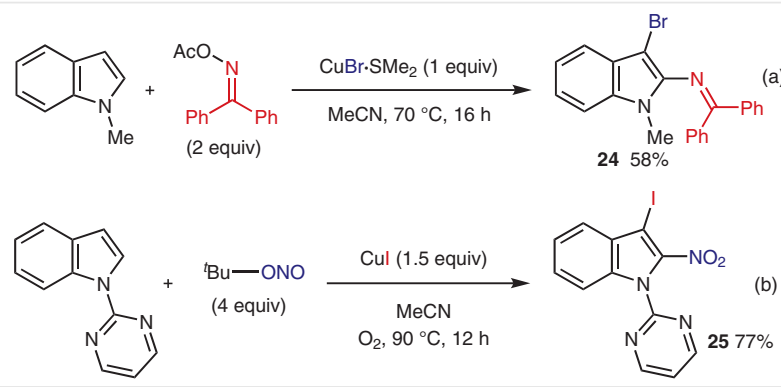

Scheme 27 (a) One-pot C-H bond difunctionalization of indoles. (b) Copper-mediated one-pot iodination and nitration of indoles

A rare example of difunctionalization involving $\mathrm{C}\left(\mathrm{sp}^{3}\right)-$ $\mathrm{H}$ bond activation was demonstrated by Baudoin ${ }^{28}$ Treatment of a 2-chloro-3-alkylthiophene or -furan with aryl bromides resulted in sequential $\mathrm{C}\left(\mathrm{sp}^{2}\right)-\mathrm{H}$ and $\mathrm{C}\left(\mathrm{sp}^{3}\right)-\mathrm{H}$ bond arylations with a single palladium catalyst having tricyclopentylphosphine $\left[\mathrm{P}(\mathrm{Cyp})_{3}\right]$ as a ligand (Scheme 28, a). Since 1-chloro-2-alkyl-5-phenylthiophene was obtained as a by-product if the reaction was quenched before complete substrate conversion, intermolecular $\mathrm{C}\left(\mathrm{sp}^{2}\right)-\mathrm{H}$ arylation occurred before intramolecular $\mathrm{C}\left(\mathrm{sp}^{3}\right)-\mathrm{H}$ arylation. Good to high diastereocontrol was achieved during $\mathrm{C}\left(\mathrm{sp}^{3}\right)-\mathrm{H}$ arylation with the desymmetrization of two isopropyl groups. Intramolecular sequential arylation of $\mathrm{C}\left(\mathrm{sp}^{2}\right)-\mathrm{H}$ and $\mathrm{C}\left(\mathrm{sp}^{3}\right)-$ $\mathrm{H}$ bonds was also conducted and revealed that the initial $\mathrm{C}\left(\mathrm{sp}^{2}\right)-\mathrm{H}$ arylation occurred site selectively at a sterically less hindered position (Scheme 28, b).
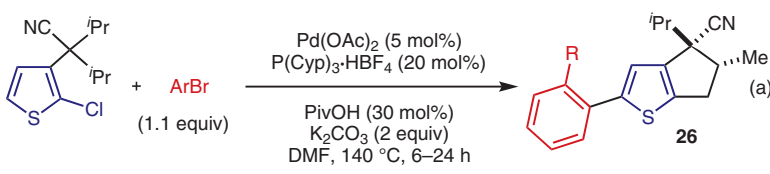

$\mathrm{R}=\mathrm{Me} \quad 82 \%(\mathrm{dr} 16 / 1)$ H $\quad 37 \%(d r>95 / 5)$ F $\quad 65 \%(\mathrm{dr} 7 / 1)$ $\mathrm{CF}_{3} \quad 79 \%(\mathrm{dr} 6 / 1)$

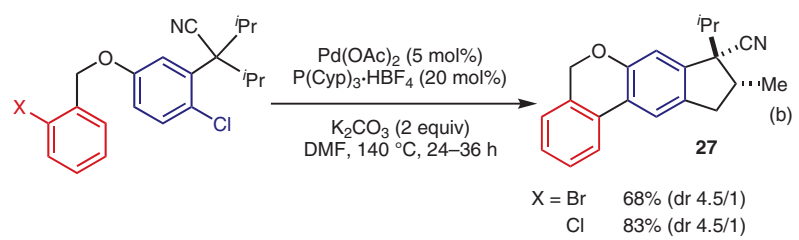

Scheme 28 (a) Difunctionalization involving $\mathrm{C}\left(\mathrm{sp}^{3}\right)-\mathrm{H}$ bond activation. (b) Intramolecular sequential arylation of $\mathrm{C}\left(\mathrm{sp}^{2}\right)-\mathrm{H}$ and $\mathrm{C}\left(\mathrm{sp}^{3}\right)-\mathrm{H}$ bonds

In 2018, Murai and Takai developed conceptually different approaches that took advantage of the high site-selective control observed in the iridium-catalyzed intermolecular dehydrogenative silylation of aromatic $\mathrm{C}-\mathrm{H}$ bonds..$^{29 a, b}$ They found that sequential treatment of triethylsilane and bis(pinacolato)diboron with quinoline in the presence of an iridium complex resulted in the site-selective introduction of both silyl and boryl groups to the quinoline ring to provide 28a (Scheme 29, a). ${ }^{30}$ Control experiments revealed that this difunctionalization occurred via initial dehydrogenative silylation at the 8-position (Scheme 29, b) followed by direct $\mathrm{C}-\mathrm{H}$ borylation at the 3- and 6-positions of the quinoline ring. ${ }^{31}$ Excess amounts of triethylsilane, the precatalyst $[\operatorname{Ir}(\mathrm{OMe})(\mathrm{cod})]_{2}$, and 5,6-dimethyl-1,10-phenanthroline (29) were required for the difunctionalization of quinolines having no substituent at the 2-position due to the competitive formation of very stable iridium-quinoline complexes in the first silylation step. Introduction of alkyl groups at the 2-position greatly improved the reaction efficiency, and variously functionalized quinoline and acridine derivatives $\mathbf{2 8}$ were obtained in a one-pot operation (Scheme 30).
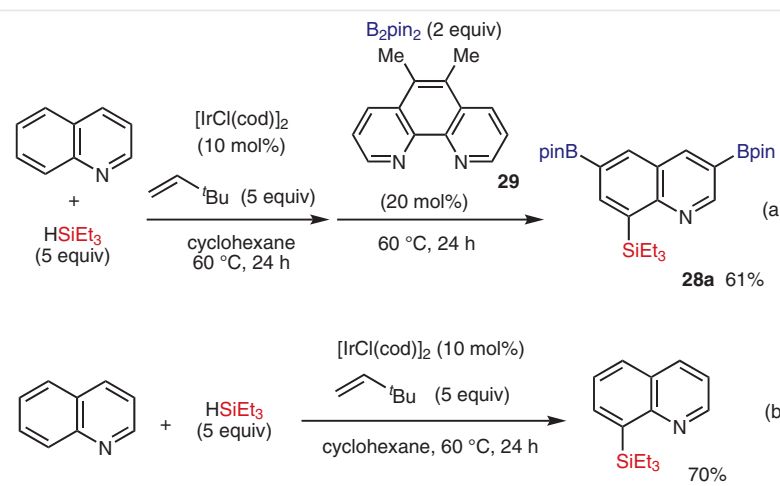

Scheme 29 (a) Site-selective introduction of silyl and boryl groups to a quinoline ring. (b) Control experiments reveal that difunctionalization occurs via initial dehydrogenative silylation at the 8-position

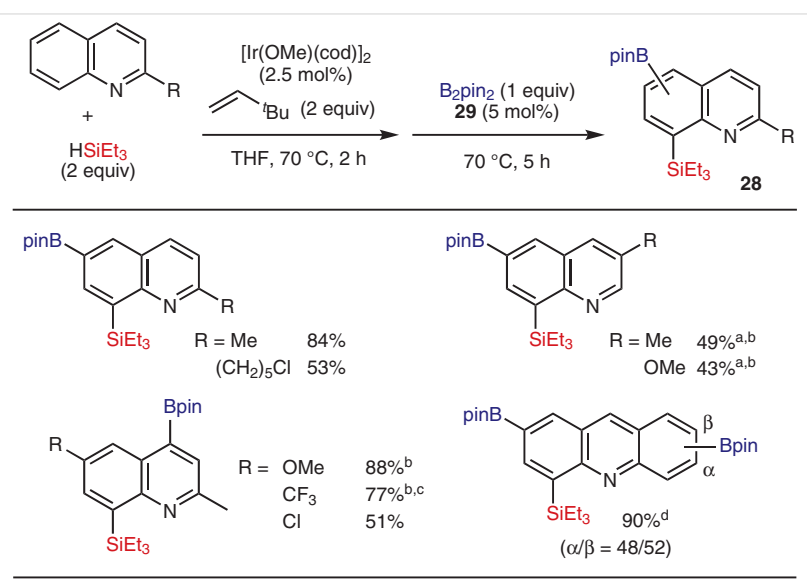

$\mathrm{a}[\operatorname{Ir}(\mathrm{OMe})(\mathrm{cod})]_{2}(10 \mathrm{~mol} \%), \mathrm{Et}_{3} \mathrm{SiH}$ (5 equiv), and $29(20 \mathrm{~mol} \%)$ were used. Both silylation and borylation for $24 \mathrm{~h} .{ }^{\text {b } 3,3-D i m e t h y l-1-b u t e n e ~(5 ~ e q u i v) ~ w a s ~}$ used. ${ }^{c}$ At $100^{\circ} \mathrm{C}$. ${ }^{\mathrm{d}}$ Bis(pinacolato)diboron (2 equiv) was used.

Scheme 30 Iridium-catalyzed site-selective sequential silylation and borylation of quinoline and acridine derivatives

In this sequential difunctionalization, silylation proceeded under chelation control by the nitrogen of the quinoline ring, whereas borylation with additional ligand $\mathbf{2 9}$ was accomplished under steric control. Addition of $\mathbf{2 9}$ in the first silylation step to prevent chelation gave an inseparable mixture of silylated quinoline regioisomers. Although 
both silylation and borylation were promoted by a single iridium catalyst, the reaction order was very important in controlling the selectivity. For example, borylation of 2-methylquinoline and 2,8-dimethylquinoline provided a mixture of mono- and diborylated quinoline derivatives (Scheme 31). Although its exact role was unclear, the silyl group at the 8-position was important for controlling the site selectivity in the second borylation step.

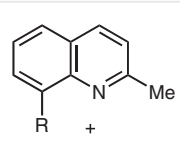

$\mathrm{B}_{2} \mathrm{pin}_{2}$ (1 equiv)
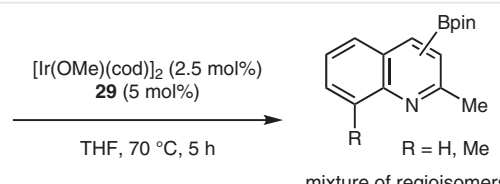

mixture of regioisomers
Scheme 31 Borylation of 2-methylquinoline and 2,8-dimethylquinoline

Electron-rich five-membered ring heteroarenes could also be applied in this sequential silylation and borylation (Scheme 32). Addition of dtbpy (4,4'-di-tert-butyl-2,2'-bipyridyl) was required for both the first silylation and second borylation steps of these substrates. A silyl group was introduced at the $\alpha$-position of these heterocycles in all cases. Adducts derived from competitive reductive dechlorination were not observed, and the reaction of the indole did not require protection of the $\mathrm{N}-\mathrm{H}$ group.

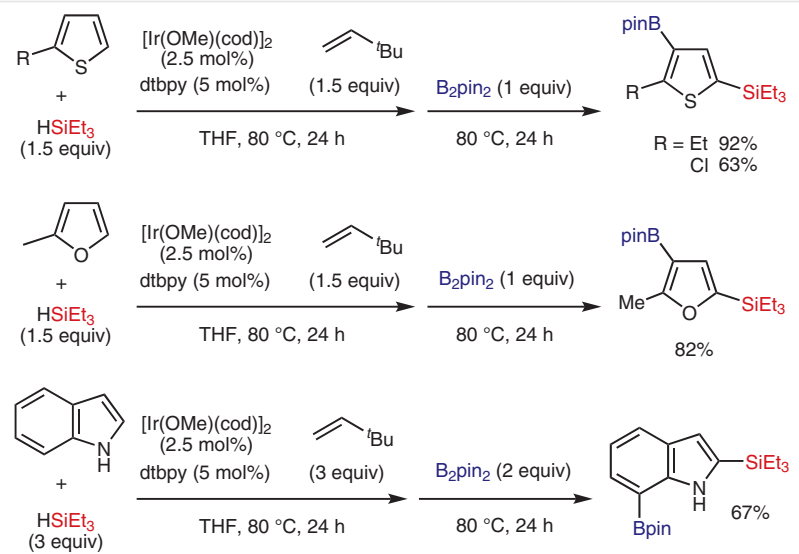

Scheme 32 Iridium-catalyzed site-selective sequential silylation and borylation of electron-rich heteroarenes

All the substrates introduced so far contained heteroatoms, which was key to controlling the site-selectivity of the difunctionalization and increased the efficiency of the overall multistep reaction sequence. Reports on the unsymmetrical difunctionalization of pure aromatic hydrocarbons, which requires $\mathrm{C}-\mathrm{H}$ activation without chelation assistance, are rare. In 2015, Murai and Takai demonstrated sequential silylation and borylation of pyrene using a similar strategy to that described above. ${ }^{29 a}$ Treatment of triethylsilane in the presence of $[\mathrm{Ir}(\mathrm{OMe})(\mathrm{cod})]_{2}$ and 3,4,7,8-tetramethyl-1,10phenanthroline followed by addition of bis(pinacolato)diboron resulted in the selective introduction of both silyl and boryl groups at the 2- and 7-positions of pyrene, respectively, leading to compound $\mathbf{3 0}$ (Scheme 33). In this difunctionalization, both silylation and borylation proceeded under steric control. The resulting adduct $\mathbf{3 0}$ could be converted into the donor-acceptor substituted pyrene $\mathbf{3 1}$ by an additional two-step transformation.

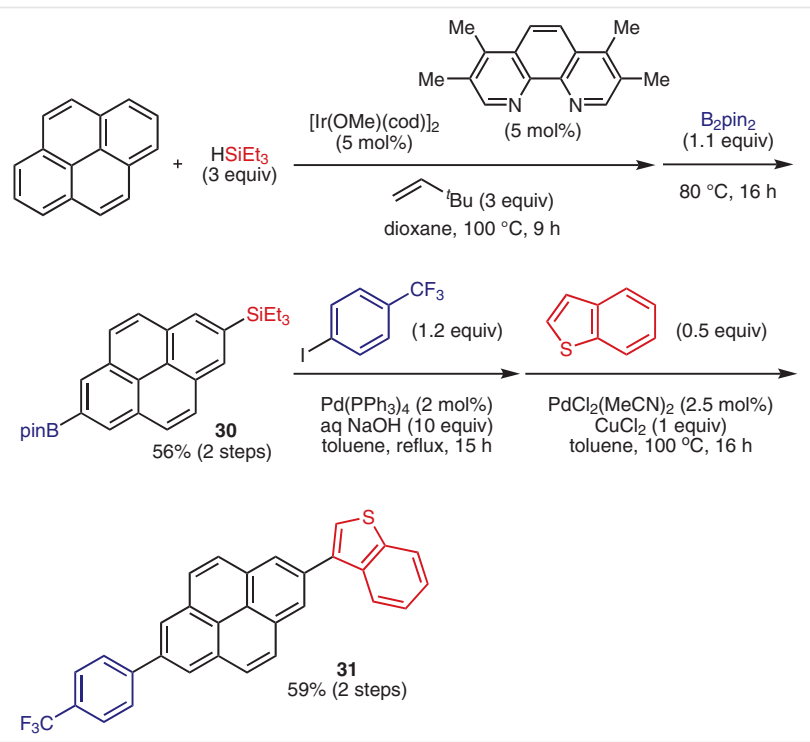

Scheme 33 Iridium-catalyzed sequential silylation/borylation of pyrene and transformation of the product

Another example reported by the same research group was the sequential diarylation of azulene. Treatment with 2-bromothiophene followed by bromobenzene led to unsymmetrically substituted diarylazulene 32, albeit in low yield (Scheme 34). ${ }^{32}$ The fused structure of the cycloheptatrienyl cation and cyclopentadienyl anion can be drawn as a uniquely polarized resonance of azulene, which might be important to fix the reactive palladium species near the C$\mathrm{H}$ bonds of the azulene. ${ }^{33}$ The yield was too low for practical use due to the difficulty of controlling the reactivity of the initial arylation with 2-bromothiophene. However, this one-pot protocol could potentially provide arylated azulene conjugates in a single operation, which is difficult to achieve by the conventional coupling reaction with generally unstable haloazulene derivatives. 


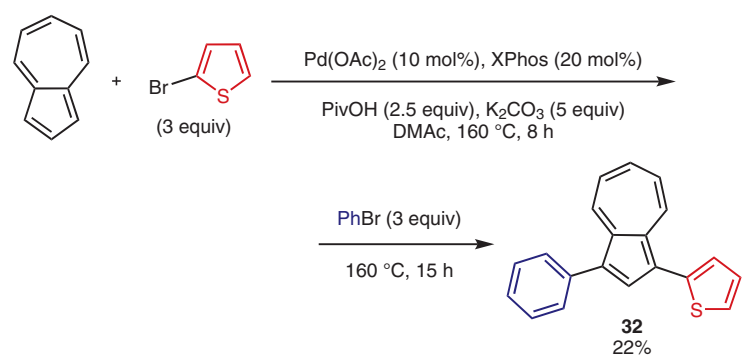

Scheme 34 The sequential diarylation of azulene

\section{Summary and Outlook}

This short review is intended to attract the reader's attention and encourage future progress in the one-pot unsymmetrical difunctionalization of two $\mathrm{C}-\mathrm{H}$ bonds. Noteworthy progress has been achieved in the last decade, and unique functionalized molecules have been constructed via one-pot operations. Although most of the products can be synthesized by stepwise transformations, the current onepot protocols allow efficient shortcuts to many molecular architectures without purification of intermediates and removal of organic and inorganic wastes. While rhodium- and palladium-based catalysis was used initially, less expensive metals, such as ruthenium, are becoming more common these days. Ruthenium catalysis has also enabled site-selective ortho- and meta-difunctionalization relative to the directing groups. Recent sequential silylation and borylation of fused aromatic compounds has also introduced a new concept of the initial functionalization creating new reactive sites for the next regioselective functionalization.

Despite these significant advances, opportunities remain for further exploration in this field. (1) Some reported protocols required the subsequent addition of reagents and additives or different reaction conditions for each step. Although automated flow reaction systems can help to execute these intricate operations, development of a real 'onepot' protocol allowing addition of all chemicals at the beginning without further additives or changes in the reaction conditions is desirable. Heterogeneous solid catalysts having several well-defined, uniform reactive sites may be suitable for this purpose. (2) Most of the reactions required heteroatom-containing directing groups to control the site selectivity of the $\mathrm{C}-\mathrm{H}$ cleavage. Leveraging the $\mathrm{C}-\mathrm{H}$ functionalization protocol without the aid of chelation control will expand the scope and applicability of the current difunctionalization. ${ }^{2 j}$ (3) Difunctionalization involving $\mathrm{C}\left(\mathrm{sp}^{3}\right)-\mathrm{H}$ bond activation remains rare. Merging with radical transformations $\mathrm{s}^{2 \mathrm{p}, 34}$ should provide several clues, although regioselective control of the $\mathrm{C}-\mathrm{H}$ cleavage may be a key issue. (4) Application to the synthesis and screening of novel biologically active molecules and functional materials is currently limited. Although the correct design of precursors and optimization of the reaction order and conditions is required, the current protocol can provide rapid access to a library of target molecules with structural and functional diversity. The use of earth-abundant metal-based catalysts, such as manganese, iron, cobalt, nickel and copper complexes, will also improve the practicality of the difunctionalization protocol.2p,35 This novel concept will find widespread application, especially in the field of pharmaceutical chemistry. ${ }^{36}$ Further synthetic potential is anticipated not only in academia but also in industry.

Finally, although this short review is as comprehensive as possible, it may not cover all relevant examples, as some of them may have been incorporated into the literature without the key words of 'difunctionalization', etc. Representative examples are highlighted, and any oversights are unintentional.

\section{Funding Information}

This work was financially supported by a Grant-in-Aid for Scientific Research (C) (No. 16K05778) from MEXT, Japan.

\section{References}

(1) (a) Tietze, L. F.; Brasche, G.; Gericke, K. M. Domino Reactions in Organic Synthesis; Wiley-VCH: Weinheim, 2006, 1st Ed.. (b) D'Souza, D. M.; Müller, T. J. J. Chem. Soc. Rev. 2007, 36, 1095. (c) Kirsch, S. F. Synthesis 2008, 3183. (d) Dömling, A.; Wang, W.; Wang, K. Chem. Rev. 2012, 112, 3083. (e) Pellissier, H. Chem. Rev. 2013, 113, 442. (f) Muzart, J. Tetrahedron 2013, 69, 6735. (g) Zeng, X. Chem. Rev. 2013, 113, 6864. (h) Sebren, L. J.; Devery, J. J. III.; Stephenson, C. R. J. ACS Catal. 2014, 4, 703. (i) Düfert, A.; Werz, D. B. Chem. Eur. J. 2016, 22, 16718. (j) Levi, L.; Müller, T. J. J. Chem. Soc. Rev. 2016, 45, 2825.

(2) (a) Colby, D. A.; Bergman, R. G.; Ellman, J. A. Chem. Rev. 2010, 110, 624. (b) Lyons, T. W.; Sanford, M. S. Chem. Rev. 2010, 110, 1147. (c) Ackermann, L. Chem. Rev. 2011, 111, 1315. (d) WencelDelord, J.; Dröge, T.; Liu, F.; Glorius, F. Chem. Soc. Rev. 2011, 40, 4740. (e) Cho, S. H.; Kim, J. Y.; Kwak, J.; Chang, S. Chem. Soc. Rev. 2011, 40, 5068. (f) Engle, K. M.; Mei, T.-S.; Wasa, M.; Yu, J.-Q. Acc. Chem. Res. 2012, 45, 788. (g) Li, B.-J.; Shi, Z.-J. Chem. Soc. Rev. 2012, 41, 5588. (h) Arockiam, P. B.; Bruneau, C.; Dixneuf, P. H. Chem. Rev. 2012, 112, 5879. (i) Yamaguchi, J.; Yamaguchi, A. D.; Itami, K. Angew. Chem. Int. Ed. 2012, 51, 8960. (j) Kuhl, N.; Hopkinson, M. N.; Wencel-Delord, J.; Glorius, F. Angew. Chem. Int. Ed. 2012, 51, 10236. (k) Rouquet, G.; Chatani, N. Angew. Chem. Int. Ed. 2013, 52, 11726. (l) Yang, L.; Huang, H. Chem. Rev. 2015, 115, 3468. (m) Liu, C.; Yuan, J.; Gao, M.; Tang, S.; Li, W.; Shi, R.; Lei, A. Chem. Rev. 2015, 115, 12138. (n) Gensch, T.; Hopkinson, M. N.; Glorius, F.; Wencel-Delord, J. Chem. Soc. Rev. 2016, 45, 2900. (o) Sun, H.; Guimond, N.; Huang, Y. Org. Biomol. Chem. 2016, 14, 8389. (p) Wang, C.-S.; Dixneuf, P. H.; Soulé, J.-F. Chem. Rev. 2018, 118, 7532. (q) Gandeepan, P.; Ackermann, L. Chem 2018, 4, 199. (r) Sambiagio, C.; Schönbauer, D.; Blieck, R.; Dao-Huy, T.; Pototschnig, G.; Schaaf, P.; Wiesinger, T.; Zia, M. F.; Wencel-Delord, J.; Besset, T.; Maes, B. U. W.; Schnürch, M. Chem. Soc. Rev. 2018, 47, 6603.

(3) For typical examples, see: (a) Sonoda, M.; Kakiuchi, F.; Chatani, N.; Murai, S. Bull. Chem. Soc. Jpn. 1997, 70, 3117. (b) Ackermann, L.; Althammer, A.; Born, R. Angew. Chem. Int. Ed. 2006, 45, 2619. 
(c) Umeda, N.; Tsurugi, H.; Satoh, T.; Miura, M. Angew. Chem. Int. Ed. 2008, 47, 4019. (d) Nakano, M.; Tsurugi, H.; Satoh, T.; Miura, M. Org. Lett. 2008, 10, 1851. (e) Hiroshima, S.; Matsumura, D.; Kochi, T.; Kakiuchi, F. Org. Lett. 2010, 12, 5318. (f) Li, B.; Bheeter, C. B.; Darcel, C.; Dixneuf, P. H. ACS Catal. 2011, 1, 1221. (g) Truong, T.; Klimovica, K.; Daugulis, O. J. Am. Chem. Soc. 2013, 135, 9342. (h) Yadav, M. R.; Rit, R. K.; Shankar, M.; Sahoo, A. K. J. Org. Chem. 2014, 79, 6123.

(4) For selected representative examples, see: (a) Yanagisawa, S.; Ueda, K.; Sekizawa, H.; Itami, K. J. Am. Chem. Soc. 2009, 131, 14622. (b) Engle, K. M.; Wang, D.-H.; Yu, J.-Q. Angew. Chem. Int. Ed. 2010, 49, 6169. (c) Gulevich, A. V.; Melkonyan, F. S.; Sarkar, D.; Gevorgyan, V. J. Am. Chem. Soc. 2012, 134, 5528. (d) Sarkar, D.; Melkonyan, F. S.; Gulevich, A. V.; Gevorgyan, V. Angew. Chem. Int. Ed. 2013, 52, 10800. (e) Kim, H. J.; Ajitha, M. J.; Lee, Y.; Ryu, J.; Kim, J.; Lee, Y.; Jung, Y.; Chang, S. J. Am. Chem. Soc. 2014, 136, 1132. (f) Deb, A.; Bag, S.; Kancherla, R.; Maiti, D. J. Am. Chem. Soc. 2014, 136, 13602. (g) Rit, R. K.; Yadav, M. R.; Ghosh, K.; Shankar, M.; Sahoo, A. K. Org. Lett. 2014, 16, 5258. (h) Zong, Y.; Rao, Y. Org. Lett. 2014, 16, 5278. (i) Sarkar, D.; Gulevich, A. V.; Melkonyan, F. S.; Gevorgyan, V. ACS Catal. 2015, 5, 6792. (j) Bera, M.; Maji, A.; Sahoo, S. K.; Maiti, D. Angew. Chem. Int. Ed. 2015, 54, 8515. (k) Yadav, M. R.; Shankar, M.; Ramesh, E.; Ghosh, K.; Sahoo, A. K. Org. Lett. 2015, 17, 1886. (l) Mboyi, C. D.; Testa, C.; Reeb, S.; Genc, S.; Cattey, H.; Fleurat-Lessard, P.; Roger, J.; Hierso, J.-C. ACS Catal. 2017, 7, 8493. (m) Shankar, M.; Ghosh, K.; Mukherjee, K.; Rit, R. K.; Sahoo, A. K. Org. Lett. 2018, 20, 5144. (n) Sen, M.; Rajesh, N.; Emayavaramban, B.; Premkumar, J. R.; Sundararaju, B. Chem. Eur. J. 2018, 24, 342.

(5) For reviews, see: (a) Grzybowski, M.; Skonieczny, K.; Butenschön, H.; Gryko, D. T. Angew. Chem. Int. Ed. 2013, 52, 9900. (b) Ye, J.; Lautens, M. Nat. Chem. 2015, 7, 863. (c) Della Ca', N.; Fontana, M.; Motti, E.; Catellani, M. Acc. Chem. Res. 2016, 49, 1389. (d) Li, S.-S.; Qin, L.; Dong, L. Org. Biomol. Chem. 2016, 14, 4554. (e) Yang, Y.; Lan, J.; You, J. Chem. Rev. 2017, 117, 8787. (f) Minami, Y.; Hiyama, T. Tetrahedron Lett. 2018, 59, 781. Annulation via a two-component coupling reaction was ignored because it results in the introduction of the same functional group into the two different $\mathrm{C}-\mathrm{H}$ bonds (i.e., not unsymmetrical difunctionalization). For selected examples, see: (g) Wang, H.; Chen, C.; Huang, Z.; Yao, L.; Li, B.; Peng, J. Synthesis 2015, 47, 2457. (h) Zheng, Q.; Luo, P.; Lin, Y.; Chen, W.; Liu, X.; Zhang, Y.; Ding, Q. Org. Biomol. Chem. 2015, 13, 4657. (i) Li, S.-S.; Lin, H.; Liu, C.-F.; Xia, Y.-Q.; Zhang, X.-M.; Dong, L. Adv. Synth. Catal. 2016, 358, 1595.

(6) Umeda, N.; Hirano, K.; Satoh, T.; Miura, M. J. Org. Chem. 2009, $74,7094$.

(7) Cong, X.; You, J.; Gao, G.; Lan, J. Chem. Commun. 2013, 49, 662.

(8) For reviews on removable and modifiable directing groups, see: (a) Rousseau, G.; Breit, B. Angew. Chem. Int. Ed. 2011, 50, 2450. (b) Zhang, F.; Spring, D. R. Chem. Soc. Rev. 2014, 43, 6906. (c) Yadav, M. R.; Rit, R. K.; Shankar, M.; Sahoo, A. K. Asian J. Org. Chem. 2015, 4, 846. (d) Ma, W.; Gandeepan, P.; Li, J.; Ackermann, L. Org. Chem. Front. 2017, 4, 1435.

(9) (a) Wang, D.-H.; Engle, K. M.; Shi, B.-F.; Yu, J.-Q. Science 2010 , 327, 315. (b) Engle, K. M.; Wang, D.-H.; Yu, J.-Q.J. Am. Chem. Soc. 2010, 132, 14137.

(10) For pioneering studies on the use of a pyridylsilyl group as a removable directing group for $\mathrm{C}-\mathrm{H}$ functionalization, see: (a) Itami, K.; Mitsudo, K.; Kamei, T.; Koike, T.; Nokami, T.; Yoshida, J.-i.J. Am. Chem. Soc. 2000, 122, 12013. (b) For a review, see: Itami, K.; Yoshida, J.-i. Synlett 2006, 157.

(11) Zhang, B.; Li, B.; Zhang, X.; Fan, X. Org. Lett. 2017, 19, 2294.
(12) (a) Ghosh, K.; Rit, R. K.; Ramesh, E.; Sahoo, A. K. Angew. Chem. Int. Ed. 2016, 55, 7821. (b) Ghosh, K.; Shankar, M.; Rit, R. K.; Dubey, G.; Bharatam, P. V.; Sahoo, A. K. J. Org. Chem. 2018, 83, 9667.

(13) Rit, R. K.; Yadav, M. R.; Ghosh, K.; Sahoo, A. K. Tetrahedron 2015, $71,4450$.

(14) Wu, Y.; Chen, Z.; Yang, Y.; Zhu, W.; Zhou, B. J. Am. Chem. Soc. 2018, $140,42$.

(15) For oxidizing directing groups, see: (a) Patureau, F. W.; Glorius, F. Angew. Chem. Int. Ed. 2011, 50, 1977. (b) Mo, J.; Wang, L.; Liu, Y.; Cui, X. Synthesis 2015, 47, 439.

(16) Li, W.; Zhao, Y.; Mai, S.; Song, Q. Org. Lett. 2018, 20, 1162.

(17) Huang, J.-R.; Song, Q.; Zhu, Y.-Q.; Qin, L.; Qian, Z.-Y.; Dong, L. Chem. Eur. J. 2014, 20, 16882.

(18) Mukherjee, K.; Shankar, M.; Ghosh, K.; Sahoo, A. K. Org. Lett. 2018, 20, 1914.

(19) Samanta, R.; Antonchick, A. P. Angew. Chem. Int. Ed. 2011, 50, 5217.

(20) Li, G.; Zhu, B.; Ma, X.; Jia, C.; Lv, X.; Wang, J.; Zhao, F.; Lv, Y.; Yang, S. Org. Lett. 2017, 19, 5166.

(21) For reviews on meta-C-H functionalization of aromatic compounds, see: (a) Yang, J. Org. Biomol. Chem. 2015, 13, 1930. (b) Dey, A.; Agasti, S.; Maiti, D. Org. Biomol. Chem. 2016, 14, 5440. (c) Leitch, J. A.; Frost, C. G. Chem. Soc. Rev. 2017, 46, 7145.

(22) A radical mechanism is proposed for the addition step of $p$-tosyl chloride onto an aromatic ring, see: (a) Saidi, O.; Marafie, J.; Ledger, A. E. W.; Liu, P. M.; Mahon, M. F.; Kociok-Köhn, G.; Whittlesey, M. K.; Frost, C. G. J. Am. Chem. Soc. 2011, 133, 19298. (b) Marcé, P.; Paterson, A. J.; Mahon, M. F.; Frost, C. G. Catal. Sci. Technol. 2016, 6, 7068.

(23) Korvorapun, K.; Kaplaneris, N.; Rogge, T.; Warratz, S.; Stückl, A. C.; Ackermann, L. ACS Catal. 2018, 8, 886.

(24) (a) Paterson, A. J.; St John-Campbell, S.; Mahon, M. F.; Press, N. J.; Frost, C. G. Chem. Commun. 2015, 51, 12807. (b) Li, J.; Warratz, S.; Zell, D.; De Sarkar, S.; Ishikawa, E. E.; Ackermann, L. J. Am. Chem. Soc. 2015, 137, 13894

(25) (a) Liu, X.-Y.; Gao, P.; Shen, Y.-W.; Liang, Y.-M. Org. Lett. 2011, 13, 4196. (b) Liu, X.; Tong, K.; Zhang, A. H.; Tan, R. X.; Yu, S. Org. Chem. Front. 2017, 4, 1354. (c) John, A.; Nicholas, K. M. Organometallics 2012, 31, 7914. (d) Tu, D.; Luo, J.; Jiang, C. Chem. Commun. 2018, 54, 2514.

(26) For reviews on $\mathrm{C}-\mathrm{H}$ functionalization of indoles, see: (a) Sandtorv, A. H. Adv. Synth. Catal. 2015, 357, 2403. (b) Leitch, J. A.; Bhonoah, Y.; Frost, C. G. ACS Catal. 2017, 7, 5618.

(27) These external bromide sources appeared to generate $\mathrm{Cu}(\mathrm{II})$ species, which were reported to promote the bromination of indoles, see: Yang, L.; Lu, Z.; Stahl, S. S. Chem. Commun. 2009, 6460.

(28) Pierre, C.; Baudoin, O. Org. Lett. 2011, 13, 1816.

(29) (a) Murai, M.; Takami, K.; Takai, K. Chem. Eur. J. 2015, 21, 4566. (b) Murai, M.; Takami, K.; Takeshima, H.; Takai, K. Org. Lett. $\mathbf{2 0 1 5}, \mathbf{1 7}, \mathbf{1 7 9 8}$. For our other contributions on the direct silylation of C-H bonds, see: (c) Ureshino, T.; Yoshida, T.; Kuninobu, Y.; Takai, K. J. Am. Chem. Soc. 2010, 132, 14324. (d) Murai, M.; Takeshima, H.; Morita, H.; Kuninobu, Y.; Takai, K. J. Org. Chem. 2015, 80, 5407. (e) Murai, M.; Matsumoto, K.; Takeuchi, Y.; Takai, K. Org. Lett. 2015, 17, 3102. (f) Murai, M.; Takeuchi, Y.; Yamauchi, K.; Kuninobu, Y.; Takai, K. Chem. Eur. J. 2016, 22, 6048. (g) Murai, M.; Okada, R.; Nishiyama, A.; Takai, K. Org. Lett. 2016, 18, 4380. (h) Murai, M.; Takeuchi, Y.; Takai, K. Chem. Lett. 2017, 46, 1044. (i) Murai, M.; Okada, R.; Asako, S.; Takai, K. Chem. Eur. J. 2017, 23, 10861. 
(30) Murai, M.; Nishinaka, N.; Takai, K. Angew. Chem. Int. Ed. 2018, $57,5843$.

(31) Direct functionalization at the $\mathrm{C}-8$ position of quinolines without conversion into quinoline $\mathrm{N}$-oxides is rare, see: (a) Iwai, T.; Sawamura, M. ACS Catal. 2015, 5, 5031. (b) Stephens, D. E.; Larionov, O. V. Tetrahedron 2015, 71, 8683.

(32) Murai, M.; Yanagawa, M.; Nakamura, M.; Takai, K. Asian J. Org. Chem. 2016, 629.

(33) For a review on direct functionalization of azulene with $\mathrm{C}-\mathrm{H}$ bond activation, see: Shi, X.; Sasmal, A.; Soulé, J.-F.; Doucet, H. Chem. Asian J. 2018, 13, 143.
(34) For a review on photoredox-catalyzed C-C bond-formation reactions, see: Xie, J.; Jin, H.; Hashmi, A. S. K. Chem. Soc. Rev. 2017, 46, 5193.

(35) Su, B.; Cao, Z.-C.; Shi, Z.-J. Acc. Chem. Res. 2015, 48, 886.

(36) (a) Galloway, W. R.; Isidro-Llobet, A.; Spring, D. R. Nat. Commun. 2010, 1, 80. (b) Duncton, M. A. J. Med. Chem. Commun. 2011, 2, 1135. (c) Caro-Diaz, E. J. E.; Urbano, M.; Buzard, D. J.; Jones, R. M. Bioorg. Med. Chem. Lett. 2016, 26, 5378. (d) Taylor, A. P.; Robinson, R. P.; Fobian, Y. M.; Blakemore, D. C.; Jones, L. H.; Fadeyi, O. Org. Biomol. Chem. 2016, 14, 6611. (e) Sengupta, S.; Mehta, G. Tetrahedron Lett. 2017, 58, 1357. 